\title{
The role of non-starch polysaccharides in determining the air-water interfacial properties of wheat, rye, and oat dough liquor constituents
}

\author{
Frederik Janssen $^{\mathrm{a}, *}$, Arno G.B. Wouters ${ }^{\mathrm{a}}$, Yannick Meeus ${ }^{\mathrm{c}}$, Paula Moldenaers ${ }^{\mathrm{c}}$, Jan Vermant ${ }^{\mathrm{d}}$, \\ Jan A. Delcour ${ }^{a}$

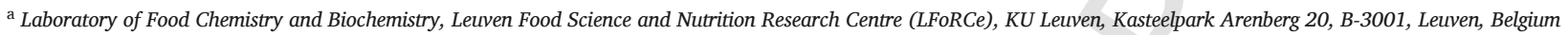 \\ c Soft Matter Rheology and Technology, Department of Chemical Engineering, KU Leuven, Celestijnenlaan 200F, 3001, Leuven, Belgium \\ d Soft Materials, Department of Materials, ETH Zürich, Vladimir-Prelog-Weg 5, 8093, Zürich, Switzerland
}

\section{A R T I C L E I N F O}

\section{Keywords}

Dough liquor

Arabinoxylan

$\beta$-D-glucan

Bulk shear rheology

Air-water interfacial shear rheology

\begin{abstract}
A B S T R A C T
Dough gas cell stability is a prerequisite for obtaining breads with high specific volume and homogeneous crumb. The contribution of cereal endogenous non-starch polysaccharides (NSPs) to gas cell stability during wheat, rye, and oat bread making is still unclear. In this work, the aqueous phases from their fermented doughs were isolated as dough liquor (DL) by ultracentrifugation. The foaming, bulk shear rheology, and air-water (A-W) interfacial properties of wheat and rye DLs (treated with and without endoxylanase) and oat DL (treated with and without both lichenase and $\beta$-D-glucosidase) were studied. Enzymatic hydrolysis drastically reduced the apparent bulk shear viscosity of the different DLs and resulted in increased and decreased moduli (or magnitude) of the complex A-W interfacial shear viscosities of wheat and rye DL, respectively. The latter implies that (non-hydrolyzed) rye DL arabinoxylan strengthens the A-W interfacial film consisting of adsorbed proteins and lipids. No measurable A-W interfacial shear viscosities were obtained for oat DL irrespective of whether its $\beta$-D-glucans were hydrolyzed or not. This is probably because lipids dominate the oat DL A-W interfaces. The knowledge generated provides a fundamental basis for specifically modifying the composition of the aqueous phase in wheat, rye, and oat doughs to improve the quality of mixed cereal breads.
\end{abstract}

\section{Introduction}

Gas cell stability is important for obtaining bread with a high specific volume and a homogeneous crumb structure. In wheat (Triticum aestivum L.) bread making, the viscoelastic gluten network plays a major role in this regard (Sroan, Bean, \& MacRitchie, 2009). Although direct evidence has - to the best of our knowledge - not yet been brought forward in literature, it has been suggested that towards the end of fermentation at least some gas cells are not completely surrounded by the gluten network because of its substantial extension upon dough expansion (Gan et al., 1990) and that from this point onwards lipids, proteins, and non-starch polysaccharides (NSPs) in the dough aqueous phase may contribute to gas cell stabilization (Gan, Ellis, \& Schofield, 1995; Sroan \& MacRitchie, 2009). Non-wheat doughs lack the viscoelastic gluten network that wheat doughs have. The argument can thus be made that gas cell stabilization by dough aqueous phase constituents is more important in non-wheat than in wheat doughs.

Some lipids and proteins are amphiphilic and have the tendency to diffuse to and adsorb at air-water (A-W) interfaces. By doing so, they lower the surface tension $(\sigma)$ of the A-W interface and, thus, the en- ergy required to create new interfacial area. Lipids which do so typically stabilize A-W interfaces by restoring spatial concentration and thus $\sigma$ gradients by diffusing to areas of lower surface concentration. When proteins adsorb at an A-W interface, they in most cases spontaneously unfold to orient their more hydrophobic regions towards the air, interact mutually, and develop a viscoelastic film that physically stabilizes the A-W interface (Murray, 2007). Such film may also prevent neighboring gas cells from merging by exerting steric hindrance and/or electrostatic repulsion.

NSPs in the dough aqueous phase may indirectly stabilize gas cell A-W interfaces (Courtin, Gelders, \& Delcour, 2001; Primo-Martín, Hamer, \& de Jongh, 2006; Sarker, Wilde, \& Clark, 1998). First, it has been observed that water-extractable arabinoxylan (WE-AX) account for the bulk viscosity $\left(\eta_{\text {bulk }}\right)$ of wheat dough liquor (DL, cfr. infra) because they bind large amounts of water (Courtin et al., 2001). With that in mind, Courtin and Delcour (2002) reasoned that WE-AX may slow down drainage of liquid from the thin films that separate adjacent gas cells in dough. Second, it has been suggested that AX interact with proteins adsorbed at A-W interfaces and thereby increase the stability of said interface (Primo-Martín et al., 2006; Sarker et al., 1998). Sarker et al. (1998) observed an increase in the foam sta-

\footnotetext{
* Corresponding author.

E-mail address: Frederik.Janssen@kuleuven.be (F. Janssen)
} 
bility of a mixed protein (bovine serum albumin) - surfactant (Tween 20) solution when purified wheat flour $A X$ was added in concentrations lower than $0.30 \mathrm{mg} / \mathrm{mL}$. These authors ascribed the improvement in foam stability to the formation of crosslinks between AX and proteins adsorbed at the A-W interface. In addition, Primo-Martín et al. (2006) reported an albeit small increase of the magnitude of the complex surface dilatational modulus $\left(\left|\mathrm{K}^{*}\right|\right)$ of wheat DL stabilized A-W interfaces when a xylanase that specifically hydrolyzes water-unextractable AX (WU-AX) was added to the dough formulation. However, in spite of the above, the extent to which proteins and NSPs interact at A-W interfaces in a bread making context remains unclear.

AX is the major NSP in wheat and rye flour. It consists of a linear backbone of $\beta$-1,4-linked D-xylopyranosyl residues. The $\mathrm{C}(O)-2$ and/ or $\mathrm{C}(O)-3$ position(s) of the xylose residues can be substituted with monomeric $\alpha$-L-arabinofuranosyl units. In turn, the $\mathrm{C}(O)-5$ position of an $\alpha$-L-arabinofuranosyl unit coupled to the $\mathrm{C}(O)$-3 position of a xylose residue can be esterified with phenolic acids such as ferulic acid (Bengtsson, Åman, \& Andersson, 1992; Cleemput, Roels, van Oort, Grobet, \& Delcour, 1993; Courtin \& Delcour, 2002; Vinkx \& Delcour, 1996). The AX population is typically divided in WE-AX and WU-AX. Of course, the AX in the aqueous film surrounding gas cells is likely for the most part WE-AX and that in DL, i.e. the supernatant obtained after ultracentrifugation of fermented dough, by definition does not contain WU-AX.

$\beta$-D-glucan is the predominant NSP in oat flour. It is composed of a quasi linear backbone of $\beta$-linked D-glucopyranosyl residues. About $85-90 \%$ of these residues are linked through two or three successive $\beta$-1,4-bonds (referred to as cellotriosyl and cellotetraosyl units, respectively) separated by $\beta-1,3$-bonds. The other $10-15 \%$ of the $\beta$-D-glucan structure consists of longer (at least five glucopyranosyl units) cellulose-like fragments linked by $\beta$-1,4-bonds (Wood, Weisz and Blackwell, 1991, 1994).

The functionality of the constituents in DL is assumed to represent that of dough aqueous phase constituents (Baker, Parker, \& Mize, 1946; MacRitchie, 1976). Studies thus far have dealt with DLs isolated from wheat dough. The emphasis has been on investigating the protein (Gerits, Pareyt, Masure, \& Delcour, 2015; Pauly, Pareyt, Fierens, \& Delcour, 2014; Salt, González-Thuillier, Chope, Penson, Tosi et al., 2018; Salt, Robertson, Jenkins, Mulholland, \& Mills, 2005) or lipid (Gerits et al., 2015; Pauly et al., 2014; Salt et al., 2018; Salt et al., 2005) composition, $\eta_{\text {bulk }}$ (Courtin et al., 2001; Pauly et al., 2014), or A-W interfacial properties (MacRitchie, 1976; MacRitchie \& Gras, 1973; Pauly et al., 2014; Primo-Martín et al., 2006; Sahi, 2003; Salt et al., 2018; Salt et al., 2006; Turbin-Orger et al., 2015) of such DLs. Overall, it has been suggested that proteins and lipids co-occur at wheat DL stabilized A-W interfaces and that WE-AX account for the wheat DL $\eta_{\text {bulk. }}$. No attention has been given to DLs isolated from doughs made with flour from cereals other than wheat.

In recent work by our group (Janssen, Wouters, Pauly, \& Delcour, 2018), some conclusions were drawn about the composition and stability of A-W interfaces formed by adsorption of wheat, rye, and oat DL constituents. In a follow-up paper (Janssen et al. submitted for publication), it was reported that proteins and lipids co-occur at wheat and rye DL stabilized A-W interfaces, whereas lipids are the predominant constituent at oat DL stabilized A-W interfaces. Furthermore, the presence of lipids at wheat and rye DL stabilized A-W interfaces was found to weaken the microstructure of the adsorbed film as observed from a pronounced increase of the interfacial shear viscosity upon defatting of the DL samples (Janssen et al. submitted for publication).

The ability of NSPs to increase $\eta_{\text {bulk }}$ and the interplay between NSPs, proteins, and lipids adsorbed at dough gas cell A-W interfaces may be of crucial importance for dough gas cell stability. We here aimed to shed light on how NSPs influence the bulk and A-W interfacial characteristics of wheat, rye, and oat DLs.

A common tool to understand the role of NSPs in cereal based processes is the use of enzymes.

AX can be depolymerized by endo- $\beta$-1,4-xylanases (EC 3.2.1.8) (further referred to as xylanases) into AX molecules of reduced molecular weight (Baker et al., 1946). Courtin and Delcour (2001) reported that the xylanase from $A$. aculeatus preferentially hydrolyzes the WE-AX population of wheat flour, whereas the xylanase from $B$. subtilis has more affinity for its WU-AX population. Similar substrate specificities have been observed with rye flour WE-AX and WU-AX populations (unpublished results).

In contrast, oat $\beta$-D-glucan is typically depolymerized by lichenase (EC 3.2.1.73). Lichenases convert it into $\beta$-D-gluco-oligosaccharides by catalyzing the hydrolysis of $\beta-1,4$ bonds. $\beta$-D-glucosidases (EC 3.2.1.21) then selectively degrade these $\beta$-D-gluco-oligosaccharides into glucose molecules by catalyzing the hydrolysis of both $\beta-1,3-$ and $\beta-1,4$ bonds (McCleary \& Nurthen, 1986).

In the present study, the role of NSPs was assessed by studying the foaming properties, the bulk shear rheology, the extent and rate at which $\gamma$ of the A-W interface decreases, and the A-W interfacial shear rheology of wheat and rye DLs (treated with and without an A. aculeatus xylanase) and oat DL (treated with and without both a $B$. subtilis lichenase and an $A$. niger $\beta$-D-glucosidase). We also investigated whether and to what extent the ability of NSPs to improve interfacial stability depends on the presence of lipids at the A-W interface. To this end, the A-W interfacial properties of the constituents in defatted wheat and rye DLs - with and without the above enzymatic treatments - were evaluated.

\section{Materials \& methods}

\subsection{Materials}

\subsubsection{Chemicals, bread making ingredients, and enzymes}

D-Allose, L-arabinose, D-xylose, D-mannose, D-galactose, D-glucose, benzoic acid, sodium borohydride, 2-octanol, and ethyl acetate were from Sigma-Aldrich (Bornem, Belgium); chloroform, methanol, bromophenol blue, trifluoroacetic acid, 1-methylimidazole, and ethanol absolute from Thermo Fisher Scientific (Aalst, Belgium); 25\% ammonia, potassium hydroxide, acetic acid, acetic anhydride, and anhydride sodium sulfate from VWR International (Oud-Heverlee, Belgium); and ethyl acetate from Merck (Darmstadt, Germany). All chemicals were at least of analytical grade. Sugar, salt, and fresh compressed yeast (AB Mauri, Dordrecht, Nederland) were bought in a local supermarket. A liquid xylanase preparation from A. aculeatus (Shearzyme 500L) was from Novozymes (Bagsvaerd, Denmark). Liquid lichenase (from B. subtilis) and $\beta$-D-glucosidase (from A. niger) preparations were those from the " $\beta$-D-glucan assay" kit of Megazyme (Bray, Ireland).

\subsubsection{Flours}

Crousti commercial bread wheat flour from Dossche Mills (Deinze, Belgium) contained $12.9 \%$ protein, $1.8 \%$ total lipids (of which $40 \%$ were free lipids and $60 \%$ were bound lipids), $2.1 \%$ total $\mathrm{AX}$ (of which $18.2 \%$ was WE-AX), $0.2 \% \beta$-D-glucan, and $0.67 \%$ ash (all on $\mathrm{dm}$ basis), and $13.6 \%$ moisture. Rye kernels (cultivar Dukato) from AVEVE (Merksem, Belgium) were conditioned to $16.0 \%$ moisture and roller milled in-house using a Bühler (Uzwil, Switserland) MLU-202 laboratory mill as in Delcour, Vanhamel, and De Geest (1989). Rye flour contained $4.0 \%$ protein, $0.9 \%$ total lipids (of which $36 \%$ were free lipids and $64 \%$ were bound lipids), $4.2 \%$ total $\mathrm{AX}$ (of which $27.9 \%$ was WE-AX), $1.1 \% \beta$-D-glucan, and $0.41 \%$ ash (all on $\mathrm{dm}$ basis), and $13.6 \%$ moisture. Commercial oat flour was from Raisio Nutrition (Raisio, Finland) and contained $13.3 \%$ protein, $7.0 \%$ total lipids (of which $72 \%$ were free lipids and $28 \%$ were bound lipids), $1.4 \%$ total AX (of which $10.9 \%$ 
was WE-AX), $2.7 \% \beta$-D-glucan, and $1.55 \%$ ash (all on dm basis), and $10.2 \%$ moisture. The methods used to determine the composition of the different flours are outlined in section 2.2.1.

\subsection{Methods}

\subsubsection{Analysis of flour composition}

All analyses described in this section were executed in triplicate.

Moisture and ash levels of flour were determined with AACCI Methods 44-19.01 and 08-01.01, respectively.

Flour protein content was determined using an adaptation of AOAC method 990.03 to an automated Dumas protein analysis system (Vario Max Cube, Elementar, Hanau, Germany).

Flour total lipid contents were determined gravimetrically as the sum of free and bound lipids as in Melis, Pauly, Gerits, Pareyt, and Delcour (2017) using an accelerated solvent extractor. Free and bound lipids were subsequently extracted from about $1.0 \mathrm{~g}$ flour with hexane and water-saturated butanol. After evaporating the butanol phase the non-lipid material present in the water-saturated butanol extract was removed by sequentially adding chloroform $(2.0 \mathrm{~mL})$, methanol $(2.0 \mathrm{~mL})$, and milli-Q water (1.8 mL) (Bligh \& Dyer, 1959). The samples were vortexed after addition of each solvent. Centrifugation $(500 \mathrm{~g}, 20 \mathrm{~min}$, $23 \pm 2{ }^{\circ} \mathrm{C}$ ) yielded a lower chloroform phase containing mostly lipids and an upper methanol-water phase containing impurities. The upper phase was discarded and the lower phase collected. After evaporating the hexane and chloroform phases, free and bound lipid levels, respectively, were quantified by weighing.

Total AX levels were the sum of xylose and arabinose levels, multiplied by 0.88 to correct for the incorporation of water during hydrolysis. Xylose and arabinose levels were determined in a gas chromatography procedure in which flour samples were sequentially subjected to acid hydrolysis (2.0 M trifluoroacetic acid, $60 \mathrm{~min}$ at $110{ }^{\circ} \mathrm{C}$ ), reduction of monosaccharides to alditols using sodium borohydride, and subsequent conversion to alditol peracetates with acetic anhydride (Englyst \& Cummings, 1984). The formed alditol peracetates were separated with an Agilent (Wilmington, DE, USA) gas chromatograph (6890 Series) equipped with a polar column (Supelco SP 2380, $30.0 \mathrm{~m}$ length, $0.32 \mathrm{~mm}$ inner diameter, $0.2 \mu \mathrm{m}$ film thickness, Bellefonte, PA, USA). Helium was used as carrier gas. WE-AX levels were determined using a procedure similar to the one described for determining the total AX content, the only two exceptions being that (i) the acid hydrolysis was performed with $2.5 \mathrm{~mL}$ of an aqueous flour extract to which was added an equal volume of $4.0 \mathrm{M}$ trifluoroacetic acid and that (ii) the arabinose level was corrected for the presence of arabinose originating from arabinogalactan peptide (arabinose to galactose ratio 0.7) for wheat (Loosveld, Grobet, \& Delcour, 1997) and rye (Van den Bulck, Swennen, Loosveld, Courtin, Brijs et al., 2005) flours. Aqueous extracts were obtained by shaking $2.0 \mathrm{~g}$ flour (on wet matter basis) in $20 \mathrm{~mL}$ water for $30 \mathrm{~min}$ at $23 \pm 2{ }^{\circ} \mathrm{C}$, followed by centrifugation $\left(1000 \mathrm{~g}, 10 \mathrm{~min}, 7^{\circ} \mathrm{C}\right)$, and filtration of the supernatant over paper.

$\beta$-D-Glucan levels were colorimetrically measured using a Megazyme (Bray, Ireland) protocol, which is also available as AACCI Method 32.23-01 (McCleary \& Nurthen, 1986). In essence, flour samples ( $80 \mathrm{mg}$, on wet matter basis) were incubated with lichenase enzyme and hydrolyzed to completion with $\beta$-D-glucosidase. The D-glucose produced was assayed using a glucose oxidase/peroxidase reagent at $510 \mathrm{~nm}$ and corrected for the presence of free D-glucose.

\subsubsection{Dough making and dough liquor isolation}

Wheat, rye, and oat DLs were isolated as in Janssen et al. (2018).

Wheat dough optimum water level and mixing time were determined using AACCI Methods 54-21.02 and 54-40.02, respectively. Flour $(100.0 \mathrm{~g})$, deionized water $(54.73 \mathrm{~mL})$, sugar $(6.0 \mathrm{~g})$, compressed fresh yeast $(5.3 \mathrm{~g})$, and salt $(1.5 \mathrm{~g})$ were mixed into dough in a pin mixer (National Manufacturing, Lincoln, NE, USA) during $210 \mathrm{~s}$. Rye or oat flour ( $265.0 \mathrm{~g}$ or $236.0 \mathrm{~g}$, respectively), deionized water (200.9 mL or $232.3 \mathrm{~mL}$, respectively), sugar (16.0 g or $14.8 \mathrm{~g}$, respectively), fresh yeast (14.1 g or $13.1 \mathrm{~g}$, respectively), and salt ( $4.0 \mathrm{~g}$ or $3.7 \mathrm{~g}$, respectively) were mixed into dough in a KitchenAid (St. Joseph, MI, USA) KPM5 mixer (60 $s$ at speed 1 and $120 s$ at speed 4).

All doughs were fermented in a National Manufacturing fermentation cabinet $\left(30.0{ }^{\circ} \mathrm{C}, 90 \%\right.$ relative humidity, $\left.126 \mathrm{~min}\right)$. Wheat doughs were sheeted in a National Manufacturing sheeter thrice during fermentation (roll gaps were $4.8 \mathrm{~mm}$ after 52 and $77 \mathrm{~min} ; 7.9 \mathrm{~mm}$ after $90 \mathrm{~min}$ ).

Fermented samples (ca. $15.0 \mathrm{~g}$, accurately weighed) of the different doughs were transferred to ultracentrifuge tubes $(38 \mathrm{~mL}$ thick polycarbonate tubes, Beckman Coulter, Brea, CA, USA), centrifuged (165,000 g, $20{ }^{\circ} \mathrm{C}, 60 \mathrm{~min}$ ) (L7 Ultracentrifuge, Beckman Coulter), and directly placed on ice to minimize potential endogenous enzymatic activity. The supernatants, i.e. the DLs, were collected in tared amber-colored Falcon tubes, weighed, freeze-dried, and stored at $-18{ }^{\circ} \mathrm{C}$ until analysis. These freeze-dried wheat, rye, and oat DL powders were used for analysis of composition (see section 2.2.3). For all other analyses, freeze-dried DL powders were dissolved (continuous stirring, $30 \mathrm{~min}, 23 \pm 2{ }^{\circ} \mathrm{C}$ ) in deionized water at various protein concentrations (depending on the analysis) as outlined below, and are further referred to as "control wheat, rye, and oat DLs' (Fig. 1).

\subsubsection{Analysis of dough liquor composition}

The compositions of the different freeze-dried DL powders were determined as in Janssen et al. (2018). Protein, lipid, AX, and $\beta$-D-glucan levels were determined in duplicate on DLs from each of two separate isolations.

DL protein $(\mathrm{N} x$ 6.25) content was determined with an adaptation of AOAC method 990.03 to an automated 1108 Elemental Analyser (Carlo Erba, Hindley Green, UK) for microgram scale samples.

DL total AX and $\beta$-D-glucan levels were determined with the same procedures as described in section 2.2.1 for the different flours. Wheat (Loosveld et al., 1997) and rye (Van den Bulck et al., 2005) DL AX levels were again corrected for the presence of arabinose originating from arabinogalactan peptides.

DL total lipid levels were determined following the extraction protocol of Bligh and Dyer (1959). Chloroform (2.0 mL), methanol $(2.0 \mathrm{~mL})$, and milli-Q water $(1.8 \mathrm{~mL})$ were sequentially added to a $10 \mathrm{~mL}$ glass tube (weight range: 17,000 to $19,000 \mathrm{mg}$ ) containing about $250 \mathrm{mg}$ accurately weighed freeze-dried DL powder. The samples were stirred using a vortex mixer after the addition of each solvent. Centrifugation $\left(500 \mathrm{~g}, 20 \mathrm{~min}, 23 \pm 2{ }^{\circ} \mathrm{C}\right)$ yielded three phases: a lower chloroform phase containing mostly lipids, a middle phase containing the remaining DL material, and an upper methanol-water phase containing impurities. The upper phase was discarded and the lower phase collected. The middle phase was extracted twice more with chloroform, methanol, and milli-Q water. The three chloroform phases were combined, the solvent was evaporated and lipid levels were gravimetrically determined using a properly calibrated XA105DU Mettler Toledo balance (Zaventem, Belgium), which has a readability of $0.01 \mathrm{mg}$.

\subsubsection{Enzymatic hydrolysis of dough liquor non-starch polysaccharides}

For foaming (see section 2.2.6), bulk shear (see section 2.2.7), and $\mathrm{A}-\mathrm{W}$ interface (see section 2.2.8) measurements, analyses were carried out on control and, hereafter so-called 'enzyme-treated' (Fig. 1) DLs at concentrations of 5.00 or $1.50 \mathrm{mg}$ protein/mL. Enzymatic treatments of wheat, rye, and oat DLs were as follows. Freeze-dried wheat and rye DL powders (see section 2.2.2) were dissolved at concentrations of 5.00 or $1.50 \mathrm{mg}$ protein $/ \mathrm{mL}$ in deionized water. Xylanase solution (containing $1.0 \mathrm{~mL}$ of xylanase preparation in $100 \mathrm{~mL}$ water) was added under gentle stirring to obtain a ratio of xylanase solution/DL dm protein of 2/ 

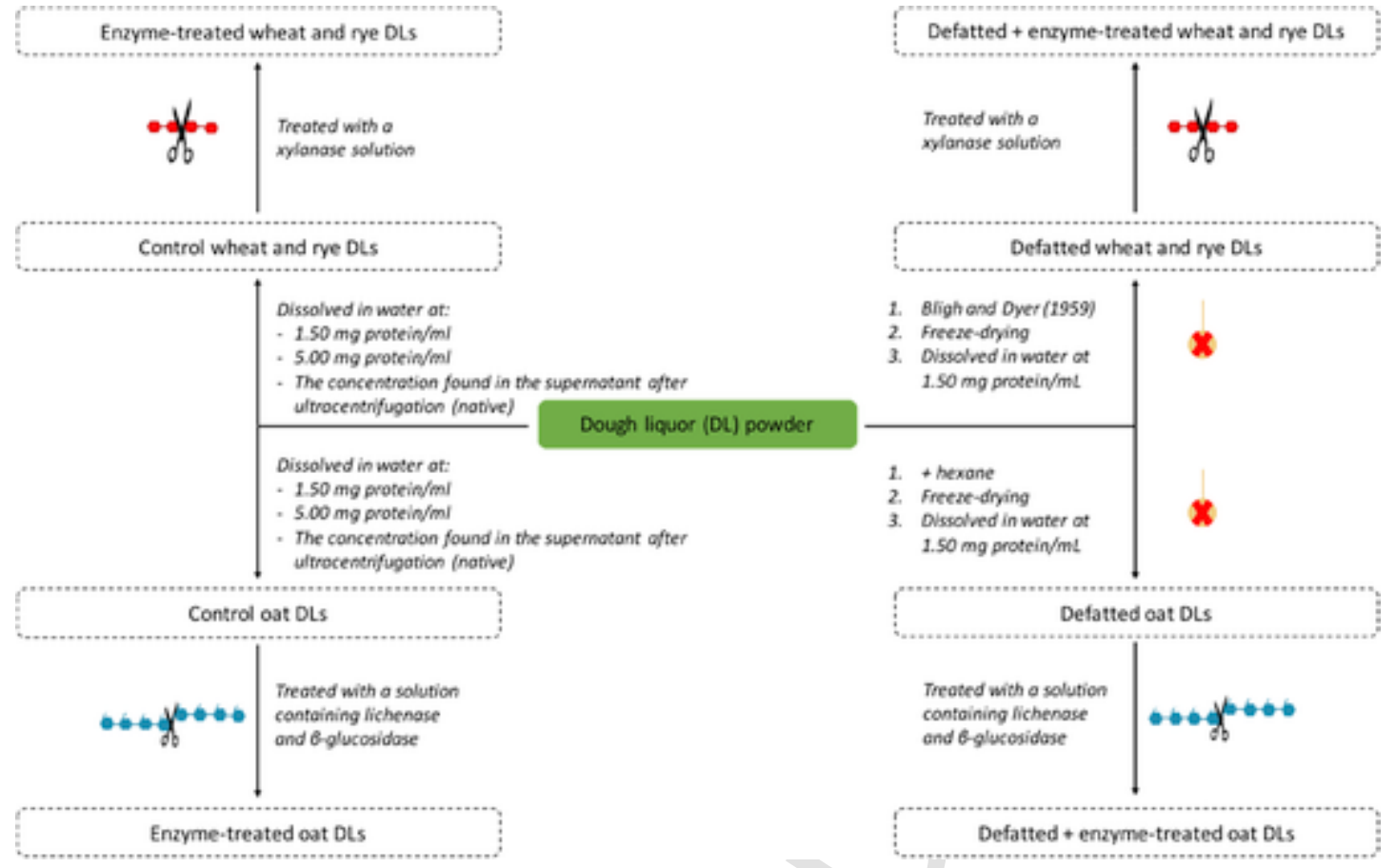

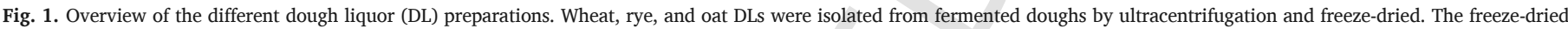

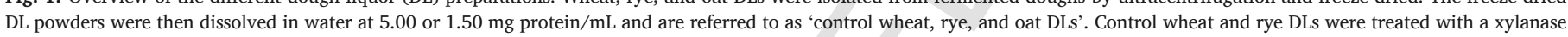

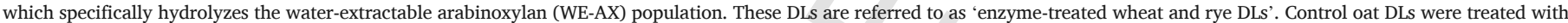

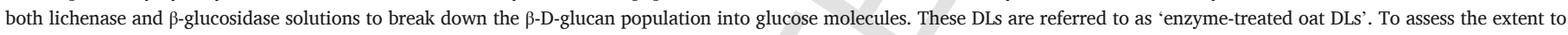

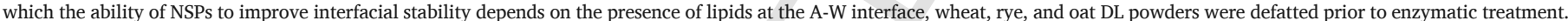

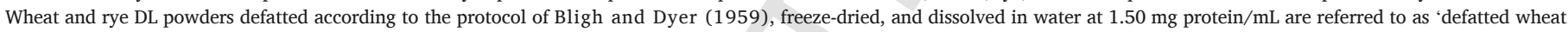

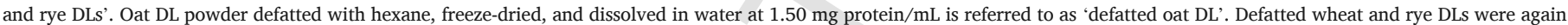
treated with xylanase, while defatted oat DL was treated with both lichenase and $\beta$-glucosidase. These DLs are referred to as 'defatted + enzyme-treated wheat, rye, and oat DLs'.

$1(\mathrm{v} / \mathrm{w})$. For example, $1.0 \mathrm{~mL}$ enzyme-treated wheat $\mathrm{DL}$ at a concentration of $5.00 \mathrm{mg} \mathrm{dm}$ protein/mL was prepared from $29.59 \mathrm{mg} \mathrm{dm}$ wheat DL (Table 1), $0.990 \mathrm{ml}$ water, and $0.010 \mathrm{ml}$ xylanase solution. Freeze-dried control oat DL powder was also dissolved as described in section 2.2 .2 at concentrations of 5.00 or $1.50 \mathrm{mg}$ protein $/ \mathrm{mL}$. Then, a solution of both lichenase and $\beta$-D-glucosidase (containing $0.50 \mathrm{ml}$ of both the lichenase and $\beta$-D-glucosidase preparations in $100 \mathrm{~mL}$ water) was added under gentle stirring to obtain ratios of enzyme solution/DL $\mathrm{dm}$ protein of $1 / 1(\mathrm{v} / \mathrm{w})$ for each of the enzymes present. For example, $1.0 \mathrm{~mL}$ enzyme-treated oat DL solution at a concentration of $5.00 \mathrm{mg} \mathrm{dm}$ protein/mL was prepared from $64.10 \mathrm{mg} \mathrm{dm}$ oat DL (Table 1), $0.990 \mathrm{ml}$ water, $0.005 \mathrm{ml}$ lichenase solution, and $0.005 \mathrm{ml}$ $\beta$-D-glucosidase solution. The above approaches were scaled to the sample volumes necessary for measuring foaming properties $(50.0 \mathrm{~mL})$, bulk shear rheometry $(4.0 \mathrm{~mL})$, and analysis by maximum bubble pressure tensiometry $(5.0 \mathrm{~mL})$, pendant drop tensiometry $(1.0 \mathrm{~mL})$, and interfacial shear rheometry (18.8 mL).

When dissolved in water at the same concentrations as used in the above outlined enzyme-treated DL solutions - no decrease in $\sigma$, as measured with the pendant drop method (see section 2.2.8.1), was ob-

Table 1a

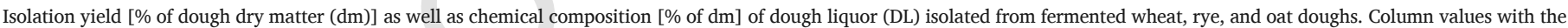

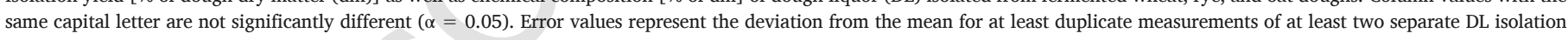
experiments.

\begin{tabular}{|c|c|c|c|c|c|c|c|c|c|}
\hline & Isolation yield ( $\%$ of $\mathrm{dm}$ ) & $\begin{array}{l}\text { Arabinoxylan (AX) level } \\
(\% \text { of dm) }\end{array}$ & & $\beta$-D-glucan level ( $\%$ of dm) & & Lipid level (\% of dm) & & Protein level (\% of dm) & \\
\hline $\begin{array}{l}\text { Wheat } \\
\text { DL }\end{array}$ & $3.4 \pm 0.4$ & $9.0 \pm 0.1$ & A & $0.6 \pm 0.1$ & A & $0.5 \pm 0.0$ & A & $16.9 \pm 0.4$ & A \\
\hline Rye DL & $10.4 \pm 0.8$ & $15.1 \pm 0.2$ & $\mathrm{~B}$ & $4.4 \pm 0.4$ & B & $1.5 \pm 0.1$ & B & $14.0 \pm 0.7$ & A \\
\hline Oat DL & $4.0 \pm 0.2$ & $2.9 \pm 0.1$ & $\mathrm{C}$ & $11.9 \pm 0.6$ & $\mathrm{C}$ & $30.2 \pm 0.5$ & $\mathrm{C}$ & $7.8 \pm 0.3$ & B \\
\hline
\end{tabular}

Table 1b

$\mathrm{dm}$, protein, lipid, arabinoxylan (AX), and $\beta$-D-glucan concentration and protein/lipid ratio (on mass basis) of wheat, rye, and oat dough liquors (DL) (all at 5.00 mg protein/mL).

\begin{tabular}{|c|c|c|c|c|c|c|}
\hline & $\mathrm{dm}(\mathrm{mg} / \mathrm{mL})$ & $\mathrm{AX}(\mathrm{mg} / \mathrm{mL})$ & $\beta$-glucan (mg/mL) & Lipids (mg/mL) & Proteins (mg/mL) & Protein/lipid ratio (-) \\
\hline Wheat DL & 29.59 & 2.66 & 0.18 & 0.15 & 5.00 & 35.71 \\
\hline Rye DL & 35.71 & 5.39 & 1.57 & 0.54 & 5.00 & 9.62 \\
\hline Oat DL & 64.10 & 1.86 & 7.63 & 18.97 & 5.00 & 0.26 \\
\hline
\end{tabular}


served. At the concentrations tested, the enzymes therefore did not interfere with the A-W interface measurements as outlined below (see section 2.2.8).

For bulk shear rheometry measurements (see section 2.2.7), analyses were also carried out on control and enzyme-treated DLs at concentrations corresponding to those in the supernatant after centrifugation in the DL isolation protocol (see section 2.2 .2$)$ ( $40.1 \mathrm{mg}$ protein/mL DL for wheat, $29.1 \mathrm{mg}$ protein/mL DL for rye, and $7.0 \mathrm{mg}$ protein/mL DL for oat). DLs at these concentrations are further referred to as 'control and enzyme-treated DLs at their native concentrations'. The respective enzymatic treatment of control DLs at their native concentrations was as above with the exception that the ratio of total enzyme solution/DL dm protein was $10 / 1(\mathrm{v} / \mathrm{w})$ instead of $2 / 1(\mathrm{v} / \mathrm{w})$. The sample volumes required for interfacial shear rheometry were $1.0 \mathrm{ml}$ (parallel-plate geometry) and $4.0 \mathrm{ml}$ (double-wall Couette geometry).

\subsubsection{Defatting of dough liquor}

Freeze-dried wheat and rye DL powders were defatted as in Janssen, Wouters et al. (submitted for publication) with an extraction protocol similar to that of Bligh and Dyer (1959) (see section 2.2.3). After three extractions, the combined methanol/water phases were added back to the middle phase to prevent loss of protein material from the DLs and the solvent was evaporated with a rotational vacuum concentrator (Q-lab, Vilvoorde, Belgium) at $40{ }^{\circ} \mathrm{C}$ and 2 mbar. The middle phase was then freeze-dried, ground, and stored at $-18{ }^{\circ} \mathrm{C}$ until analysis.

Freeze-dried oat DL powder was defatted as in Janssen, Wouters et al. (submitted for publication) with hexane. Hexane $(5.0 \mathrm{~mL})$ was added to $250 \mathrm{mg}$ of freeze-dried oat DL powder. The suspension was mechanically shaken [175 movements per $\mathrm{min}, 30 \mathrm{~min}$, room temperature] and centrifuged (2000 $\mathrm{g}, 15 \mathrm{~min})$. The supernatant was discarded and the extraction repeated twice more. The remaining DL material was freeze-dried, ground, and stored at $-18{ }^{\circ} \mathrm{C}$ until analysis.

Each of the two defatting procedures were performed in six-fold on DL powders from each of two separate isolations. Protein levels of these defatted and freeze-dried wheat, rye, and oat DL powders were determined as described in section 2.2.3. Defatted and freeze-dried wheat, rye, and oat DL powders were dissolved in deionized water at various protein concentrations as described in section 2.2.2 and are further referred to as 'defatted wheat, rye, and oat DLs' (Fig. 1).

To assess the extent to which the ability of NSPs to affect interfacial stability depends on the presence of lipids at the A-W interface, defatted wheat, rye, and oat DLs were subjected to the same enzymatic treatment described in section 2.2.4 for control wheat, rye, and oat DLs. The resulting defatted and enzyme-treated wheat, rye, and oat DLs are further referred to as 'defatted + enzyme-treated wheat, rye, and oat DLs' (Fig. $1)$.

\subsubsection{Analysis of dough liquor foaming properties}

A whipping test was carried out to determine foaming characteristics of control and enzyme-treated wheat, rye, and oat DLs at $5.00 \mathrm{mg}$ protein/mL as in Janssen et al. (2018). DL aliquots $(50.0 \mathrm{~mL})$ in a graduated glass cylinder (internal diameter: $60 \mathrm{~mm}$ ) were stirred for $130 \mathrm{~s}$ at $2 \mathrm{k}$ rotations/min using a rotating propeller (outer diameter: $45.0 \mathrm{~mm}$, thickness: $0.4 \mathrm{~mm}$ ) fixed on a cylindrical bar (diameter: $6.0 \mathrm{~mm}$ ) in a water bath at $30{ }^{\circ} \mathrm{C}$. Immediately after stirring, the propeller was removed and the glass cylinder covered with Parafilm M (Bemis, Neenah, WI, USA) to minimize foam disruption by air circulation. The foaming capacity is the foam volume $180 \mathrm{~s}$ after the start of stirring. The foam volume was calculated from its height and the internal diameter of the cylinder and monitored over a $60 \mathrm{~min}$ period. The rate and extent of the decline of the foam volume over time is a measure for foam stability. Foaming properties were single measurements on DLs from each of three separate isolations.

\subsubsection{Dough liquor bulk shear rheometry}

The bulk shear rheological parameters were monitored with a stress-controlled rheometer (MCR501, Anton Paar, Graz, Austria). The steady state bulk shear viscosities of control wheat, rye, and oat DLs at their native concentrations $(40.1,29.1$, and $7.0 \mathrm{mg}$ protein/mL, respectively) were measured as function of shear rate (logarithmic sweep between 0.1 and $100 \mathrm{~s}^{-1}, 5$ measurement points per decade) using a parallel-plate geometry (diameter: $25.0 \mathrm{~mm}$, gap size: $1.0 \mathrm{~mm}$ ). A solvent trap was used to prevent dehydration. Samples were allowed to rest 2 min prior to performing measurements.

Both for samples which had been submitted to enzymatic hydrolysis of NSPs and at lower DL concentrations, the parallel-plate geometry was not suited for bulk shear rheometry measurements. Instead, the steady state bulk shear viscosities of enzyme-treated wheat, rye, and oat DLs at their native concentrations and those of control and enzyme-treated wheat, rye, and oat DLs (all at $1.50 \mathrm{mg}$ protein/mL) were measured as function of shear rate (logarithmic sweep between 1 and $1000 \mathrm{~s}^{-1}, 5$ measurement points per decade) with a double-wall Couette geometry (DG26.7, inner radius: $12.33 \mathrm{~mm}$, outer radius: $13.33 \mathrm{~mm}$, bob length: $40.00 \mathrm{~mm}$ ). A $4.0 \mathrm{~mL}$ aliquot was gently transferred to the double wall sample holder. Samples were again allowed to rest for $2 \mathrm{~min}$ prior to performing measurements.

In both experimental setups, the temperature $\left(21^{\circ} \mathrm{C}\right)$ was kept constant using a Peltier heating element. A minimum torque limit of $0.1 \mu \mathrm{N} \mathrm{m}$ was used to obtain reliable data. Bulk shear rheological properties were single measurements on DLs from each of two separate isolations.

\subsubsection{Analysis of dough liquor air-water interfacial properties}

The surface stress $\left(\sigma_{s}\right)$ in the principal direction $\mathbf{n}$ of rheologically complex A-W interfaces such as those of gas cells in bread dough is composed of surface tension $[\sigma(\Gamma, \mathrm{T})$, which only depends on the excess concentration $\Gamma$ and the temperature T] and surface extra stress $\left(\tau_{n n}\right)$ contributions (Jaensson \& Vermant, 2018):

$\sigma_{s}=\sigma(\Gamma, T)+\tau_{n n}$

These contributions are not separated in pendant drop tensiometry measurements (section 2.2.8.1). Thus, when $\tau_{\mathrm{nn}}$ is not negligible, which is the case for the A-W interfaces studied here, the parameters obtained with each of these methods in fact represents $\sigma_{s}$ rather than $\sigma(\Gamma, \mathrm{T})$. However, obtained $\sigma_{s}$ values over time yield information about the diffusion and adsorption of DL constituents at A-W interfaces. Shear rheometry measurements (section 2.2 .8 .2 ) provide information about the magnitude of $\tau$ of the film formed at the A-W interface.

2.2.8.1. (Oscillating) pendant drop tensiometry The decrease of $\sigma_{s}$ over time was measured at ambient temperature $\left(23 \pm 2{ }^{\circ} \mathrm{C}\right)$ using a Theta optical tensiometer (Attension, Biolin Scientific, Stockholm, Sweden) as in Janssen et al. (2018). Control and enzyme-treated wheat, rye, and oat DLs (all at $5.00 \mathrm{mg}$ protein $/ \mathrm{mL}$ ) were introduced in the device to create a pendant drop with a fixed volume $(8.0 \mu \mathrm{l})$. The $\sigma_{s}$ was monitored over $15 \mathrm{~min}$ (with 1.4 frames recorded/s in the first $5 \mathrm{~min}$ and 0.14 frames recorded/s in the last $10 \mathrm{~min}$ ). Immediately afterwards, the droplet was sinusoidally oscillated (volume amplitude of approximately $1.0 \mu \mathrm{l}$ or $12.5 \%$ of droplet volume) at $0.8 \mathrm{~Hz}$ (with 6.9 frames recorded/ $\mathrm{sec}$ ) for 10 cycles. The magnitude of $\left|\mathrm{K}^{*}\right|$ of the film formed at the A-W interface was calculated by drop shape analysis and Fourier transformations and represents the change in $\sigma_{s}$ relative to the change in the natural logarithm of the surface area A:

||$K^{*} \mid=\sqrt{K^{\prime 2}+K^{\prime \prime}}=\frac{\mathscr{F}\left(\Delta \sigma_{s}\right)}{\mathscr{F}(\Delta \ln A)}$ 
After each measurement, the device was thoroughly cleaned and $\sigma_{s}$ of pure water was verified to be $72.0 \pm 0.50 \mathrm{mN} / \mathrm{m}$ as above before initiating a new measurement. All pendant drop measurements were performed in duplicate on DLs from each of two separate isolations.

2.2.8.2. Stress-controlled interfacial shear rheometry The linear viscoelastic rheological material functions of DL stabilized A-W interfaces were measured in simple shear deformations with a stress-controlled rheometer (Discovery HR-3, TA Instruments, New Castle, DE, USA) equipped with the platinum double wall ring (DWR) geometry from TA Instruments. The DWR had the following dimensions: inner radius: $34.50 \mathrm{~mm}$, outer radius: $35.50 \mathrm{~mm}$, ring width: $1.00 \mathrm{~mm}$. Aliquots $(18.80 \mathrm{~mL})$ of control, enzyme-treated, defatted, and defatted + enzyme-treated wheat, rye, and oat DLs at $1.50 \mathrm{mg}$ protein/mL were gently transferred to a double wall Teflon sample holder. In this set up, DL surface-active constituents spontaneously adsorbed at the A-W interface. Time sweeps were performed at $21{ }^{\circ} \mathrm{C}$ for 126 min (i.e. the total fermentation time during the bread making protocol) at an oscillation frequency of $3.14 \mathrm{rad} / \mathrm{s}$ or $0.50 \mathrm{~Hz}$ and a surface shear stress amplitude of $16.23 \mu \mathrm{N}$ / $\mathrm{m}$, which was within the linear viscoelastic regime for all DLs (see supplementary information). Oscillatory frequency sweeps $(0.50-5.00 \mathrm{~Hz})$ revealed that the obtained moduli increased linearly with the applied frequency. The oscillation frequency was thus relevant. Boussinesq (Bq) numbers were calculated to evaluate to which extent the bulk phase viscosity influenced the A-W interfacial viscosity measurements (Renggli, Alicke, Ewoldt, \& Vermant, 2020). They were calculated with the magnitude of the initial modulus of the complex surface shear viscosity $\left(\left|\eta_{\mathrm{s}} *\right|\right)$ after positioning the ring at the A-W interface. As Bq numbers were lower than 100, the components of $\left|\eta_{\mathrm{s}}{ }^{*}\right|$ were corrected using an iterative solver to take into account the coupling of the flow in the subphase with the A-W interface (Vandebril, Franck, Fuller, Moldenaers, \& Vermant, 2010). This was essential to obtain the exact deformation profile and shear rates at the A-W interface. The steady state bulk phase shear viscosities of control, enzyme-treated, defatted, and defatted + enzyme-treated wheat, rye, and oat DLs at $1.50 \mathrm{mg}$ protein $/ \mathrm{mL}$ were monitored at $21{ }^{\circ} \mathrm{C}$ as described in section 2.2.7. Thus, the magnitude of $\left|\eta^{*}{ }_{s}\right|$ in Fig. 5, 6, and 7 and of the phase angle $\left(\delta_{s}\right)$ in the Figures in the supplementary information were calculated taking the subphase coupling into account. The $\left|\eta{ }^{*}\right|$ can also be decomposed in an elastic part ( $\eta{ }^{\prime \prime} s$, which is out of phase with the deformation rate) and a viscous part $\left(\eta^{\prime}\right.$ s, which is in phase with the deformation rate). A-W interfacial shear rheology experiments were single (defatted and defatted + enzyme-treated DLs) or duplicate (control and enzyme-treated DLs) measurements on DLs from each of two separate isolations.

\subsubsection{Statistical analyses}

Data were analyzed with statistical software JMP pro 12 (SAS Institute, Cary, NC, USA). Significant differences, at a significance level of $\alpha=0.05$, were identified using one-way analysis of variance combined with the post-hoc Tukey's honest significant difference (HSD) test.

\section{Results and discussion}

\subsection{Dough liquor composition}

Table 1a lists isolation yields as well as AX, $\beta$-D-glucan, lipid, and protein levels of wheat, rye, and oat DLs. The isolation yield of DLs (expressed as percentage of dough $\mathrm{dm}$ ) decreased in the order rye $(10.4 \%$ of $\mathrm{dm})$, oat $(4.0 \%$ of $\mathrm{dm})$, and wheat $(3.4 \%$ of $\mathrm{dm})$ DLs. AX was the major NSP in wheat and rye DLs (9.0 and $15.1 \%$ of DL dm, respectively) and $\beta$-D-glucan that in oat DL (11.9\% of DL dm). The level of $\mathrm{AX}$ was higher in rye than in wheat DL probably because of the higher level of WE-AX in rye $(1.2 \%$ of $\mathrm{dm})$ than in wheat $(0.4 \%$ of $\mathrm{dm})$ flour (see section 2.1.2). Lipid levels were high in oat (30.2\% of DL dm)
DL and much lower in rye (1.5\% of DL dm) and wheat $(0.5 \%$ of DL dm) DLs. The protein content decreased in the order wheat $(16.9 \%$ of DL $\mathrm{dm})$, rye $(14.0 \%$ of DL $\mathrm{dm})$, and oat $(7.8 \%$ of DL $\mathrm{dm})$ DLs.

In what follows, the foaming properties, bulk shear rheology, and A-W interfacial properties of control and enzyme-treated wheat, rye, and oat DLs are documented. DLs were analyzed in solutions at their native concentrations (bulk shear rheometry), at $5.00 \mathrm{mg}$ protein $/ \mathrm{mL}$ (foaming properties and pendant drop tensiometry), and at $1.50 \mathrm{mg}$ protein $/ \mathrm{mL}$ (both bulk and interfacial shear rheometry). Because the freeze-dried DL powders had different protein levels (Table 1a), such standardization of course had consequences for the concentrations of the other DL constituents. Table $1 \mathrm{~b}$ lists the AX, $\beta$-D-glucan, lipid, and protein concentrations and protein/lipid ratios (on a mass basis) of the different control DLs at $5.00 \mathrm{mg}$ protein/mL.

\subsection{Dough liquor foaming properties}

Fig. 2 shows foam volume over time plots of control and enzyme-treated wheat, rye, and oat DLs (all at $5.00 \mathrm{mg}$ protein/mL). Constituents in enzyme-treated wheat and rye DLs had a significantly $(\mathrm{P}<0.05)$ lower foaming capacity than those in their respective control DLs. Foam from enzyme-treated wheat DL disappeared within 5 min after the start of stirring (Fig. 2). Similarly, only $17 \%$ of the foam remained after $60 \mathrm{~min}$ for enzyme-treated rye DL compared to $31 \%$ for control rye DL (Fig. 2). Foam could not be produced from control oat DL (at $5.00 \mathrm{mg}$ protein $/ \mathrm{mL}$ ) due to its very high apparent viscosity. This issue was overcome by enzymatic hydrolysis of oat DL $\beta$-D-glucan. Although enzyme-treated oat DLs (all at $5.00 \mathrm{mg}$ protein $/ \mathrm{mL}$ ) produced a low initial foam volume of $23 \mathrm{~mL}$, the foams were rather stable, with $64 \%$ of the foam remaining after $60 \mathrm{~min}$ (Fig. 2). At $2.50 \mathrm{mg}$ protein/ $\mathrm{mL}$ (graphs not shown), the constituents in enzyme-treated oat DL had a significantly $(\mathrm{P}<0.05)$ lower foaming capacity than those in control oat DL, which was in line with what was observed for wheat and rye DLs. The stabilities of control and enzyme-treated oat DLs at $2.50 \mathrm{mg}$ protein/mL were roughly similar, with $67 \%$ and $75 \%$, respectively, of the foam remaining after $60 \mathrm{~min}$.

Thus, hydrolysis of wheat and rye DL AX had an overall negative impact on the foaming capacity of the obtained foams. A similar but less pronounced effect was observed for foams from oat DLs treated with lichenase and $\beta$-D-glucosidase. The data thus demonstrate that NSPs contribute to the foaming properties of DL. This can probably be explained by differences in $\eta_{\text {bulk }}$ and/or the structure and stability of the adsorbed A-W interfacial film surrounding the gas cells.

\subsection{Dough liquor bulk shear rheometry}

Fig. 3 shows $\eta_{\text {bulk }}$ as function of shear rate for control and enzyme-treated wheat, rye, and oat DLs at $1.50 \mathrm{mg}$ protein $/ \mathrm{mL}$ as well as at their native concentrations. At $1.50 \mathrm{mg}$ protein $/ \mathrm{mL}$, control oat $\mathrm{DL}$ had slightly higher $\eta_{\text {bulk }}$ values for most shear rates measured than control rye and wheat DLs. In addition, control wheat, rye, and oat DLs at $1.50 \mathrm{mg}$ protein $/ \mathrm{mL}$ had higher $\eta_{\text {bulk }}$ values than their enzymatically treated counterparts. However, the difference in $\eta_{\text {bulk }}$ of control and enzyme-treated wheat DLs at $1.50 \mathrm{mg}$ protein/mL (which was approximately $0.26 \mathrm{mPa}$ s over shear rates between 100 and $1000 \mathrm{~s}^{-1}$ ) seems small because the curves are shown in a log-log plot. Moreover, also for both other enzyme-treated DLs (oat and rye at $1.50 \mathrm{mg}$ protein/ $\mathrm{mL}$ ), $\eta_{\text {bulk }}$ values were similar to that of water, which implies that the NSPs had been degraded due to the enzymatic treatment. At their native concentrations, all DLs displayed shear thinning behavior as reflected in a decrease of $\eta_{\text {bulk }}$ when shear rate increased and therefore were non-Newtonian fluids. Thus, the $\eta_{\text {bulk }}$ values reported here are in fact apparent values. Control rye DL at its native concentration had much higher $\eta_{\text {bulk }}$ values over all shear rates measured (with a decrease in $\eta_{\text {bulk }}$ 

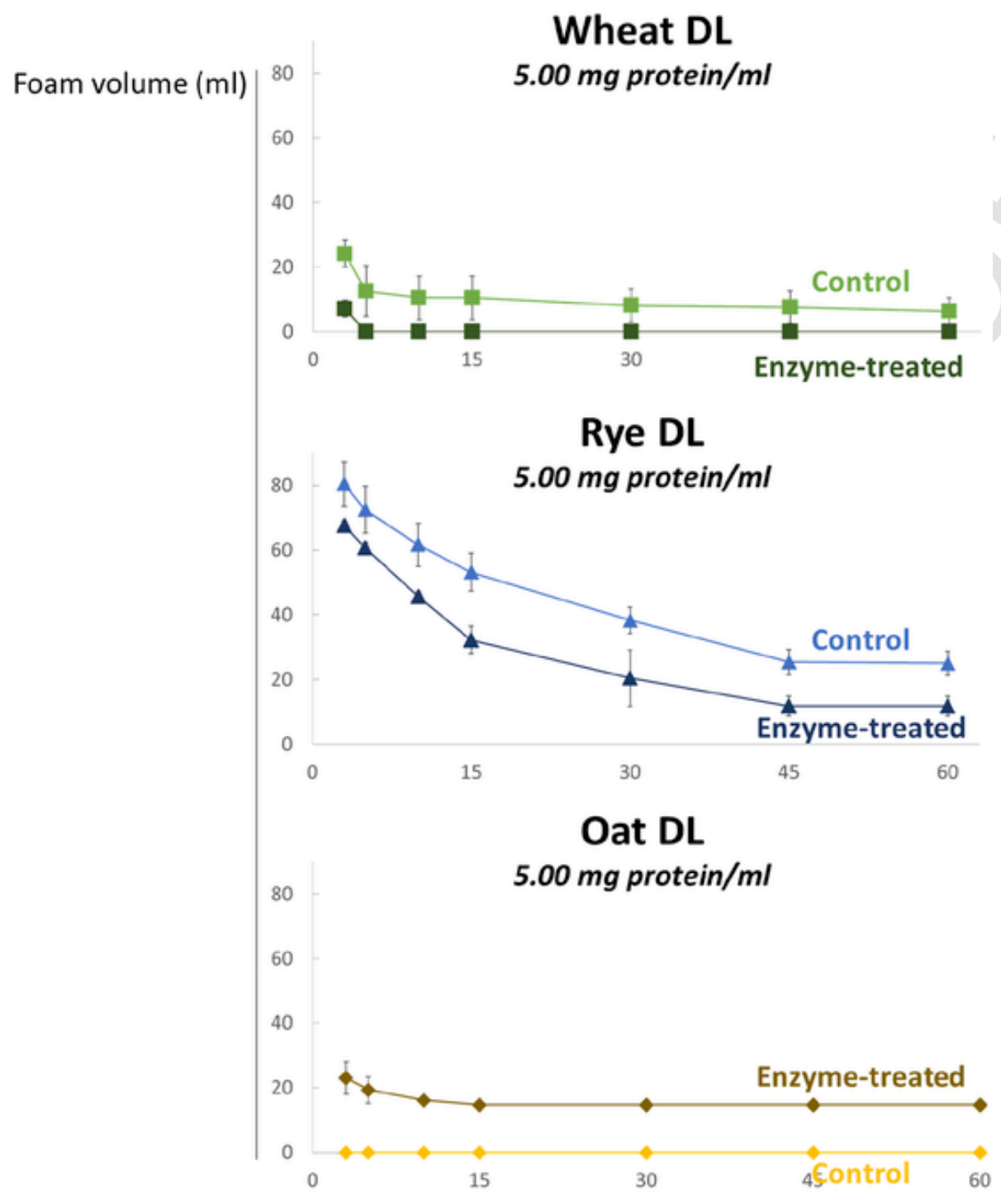

\section{Time (min)}

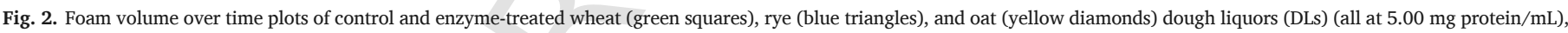

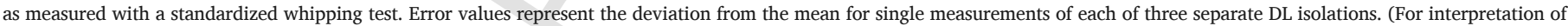
the references to color in this figure legend, the reader is referred to the Web version of this article.)

from $631,272 \mathrm{mPa} s$ at $0.1 \mathrm{~s}^{-1}$ to $5511 \mathrm{mPa} \mathrm{s}$ at $100 \mathrm{~s}^{-1}$ ) than control oat (with a decrease in $\eta_{\text {bulk }}$ from $31,100 \mathrm{mPa}$ s at $0.1 \mathrm{~s}^{-1}$ to $769 \mathrm{mPa} \mathrm{s}$ at $100 \mathrm{~s}^{-1}$ ) and control wheat (with a decrease in $\eta_{\text {bulk }}$ from $677 \mathrm{mPa} \mathrm{s}$ at $0.1 \mathrm{~s}^{-1}$ to $202 \mathrm{mPa} \mathrm{s}$ at $100 \mathrm{~s}^{-1}$ ) DLs at their native concentrations. Similar to what was the case at $1.50 \mathrm{mg}$ protein $/ \mathrm{mL}$, the $\eta_{\text {bulk }}$ values of control wheat, rye, and oat DLs at their native concentrations were significantly $(\mathrm{P}<0.05)$ higher than those of their enzymatically treated counterparts. Indeed, at shear rates of 0.1 and $100 \mathrm{~s}^{-1}$, enzyme-treated wheat, rye, and oat DLs at their native concentrations had $\eta_{\text {bulk val- }}$ ues of 252 and $6 \mathrm{mPa} \mathrm{s}, 18,460$ and $274 \mathrm{mPa} \mathrm{s}$, and 16 and $2 \mathrm{mPa} \mathrm{s}$, respectively. Thus, both at $1.50 \mathrm{mg}$ protein/mL as well as at their native concentrations, enzymatic hydrolysis of $\mathrm{AX}$ in control wheat and rye DLs and of $\beta$-D-glucan in control oat DL sufficed to substantially reduce $\eta_{\text {bulk }}$ of their respective enzyme-treated DLs. In what follows, the term 'non-hydrolyzed $\mathrm{AX}$ ' refers to the $\mathrm{AX}$ population present in control wheat and rye DLs and thus to the AX population prior to enzymatic hydrolysis.
The above showed that NSPs contribute substantially to $\eta_{\text {bulk }}$ of wheat, rye, and oat DLs and, hence, probably also to $\eta_{\text {bulk }}$ of the aqueous phase in their respective doughs. It is therefore highly likely that NSPs slow down drainage of liquid from the aqueous film separating adjacent gas cells and provide resistance to coalescence. This phenomenon is probably more important in non-wheat than in wheat doughs as it can be expected that drainage of the dough aqueous phase in between gas cells occurs much slower in wheat doughs due to the high viscoelasticity of the gluten network (Mills, Wilde, Salt, \& Skeggs, 2003; Pauly \& Delcour, 2018).

\subsection{Dough liquor air-water interfacial properties}

\subsection{1. (Oscillating) pendant drop tensiometry}

Fig. 4 shows $\sigma_{s}$ over time plots and $\left|\mathrm{K}^{*}\right|$ values of pendant droplet A-W interfaces stabilized by control and enzyme-treated wheat, rye, and oat DL constituents (all at $5.00 \mathrm{mg}$ protein $/ \mathrm{mL}$ ). The decrease in $\sigma_{s}$ of control oat DL stabilized A-W interfaces was much more pro- 

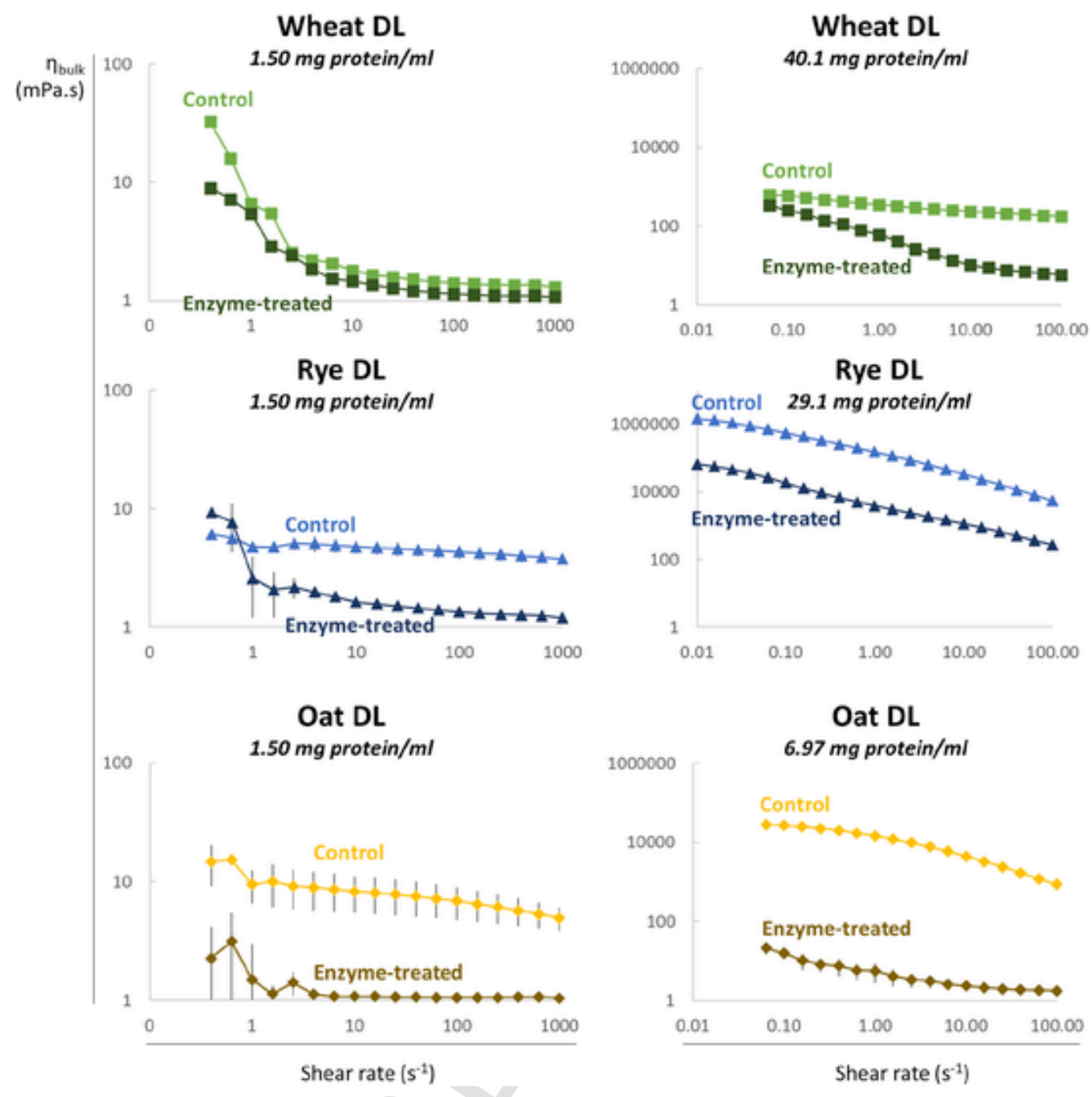

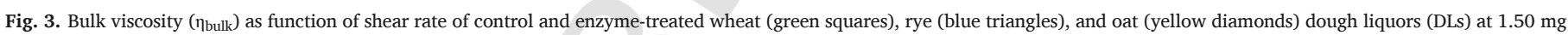

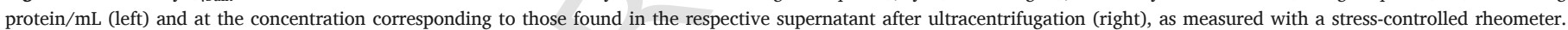

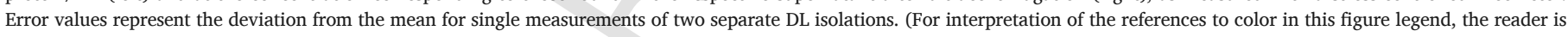
referred to the Web version of this article.)

nounced than was the case for control wheat or rye DL stabilized A-W interfaces. This can be because lipids are the predominant DL constituent at oat DL A-W interfaces (Janssen et al. submitted for publication). Enzymatic hydrolysis of wheat or rye DL AX or of oat DL $\beta$-D-glucan had no impact on the $\sigma_{s}$ vs. time plots. Indeed, the molecular structures of AX and $\beta$-D-glucan are hydrophilic. Thus, they will most likely not adsorb at interfaces. In addition, the molecular weights of non-hydrolyzed AX and $\beta$-D-glucan are much higher than those of proteins and lipids. Thus, even if they would adsorb at interfaces, the rate at which they diffuse to the interface would be much lower than that of proteins and lipids. All this implies that non-hydrolyzed $\mathrm{AX}$ and $\beta$-D-glucan molecules did not adsorb at the A-W interface themselves, but also that they did not influence the diffusion and adsorption behavior of other DL constituents.

After 15 min, pendant droplets were subjected to sinusoidal volume oscillations from which the magnitude of $\left|\mathrm{K}^{*}\right|$ a measure for the effective viscoelasticity of the adsorbed film, was calculated (see section 2.2.8.1). High $\left|\mathrm{K}^{*}\right|$ values indicate that a strong elastic response is obtained, which can often be related to high foam stability as it delays gas cell coalescence and disproportionation (Murray, 2007). In general, $\left|\mathrm{K}^{*}\right|$ values obtained for DL stabilized A-W interfaces should be in- terpreted with care as the pendant drop technique was originally developed for $\mathrm{A}-\mathrm{W}$ interfaces characterized by an isotropic $\sigma$, in absence of extra or deviatoric viscoelastic contributions (Jaensson \& Vermant, 2018). In such case a more elaborate analysis is required (Knoche et al., 2013; Nagel, Tervoort, \& Vermant, 2017). As we will show in section 3.4.2, this was certainly not the case for the control and enzyme-treated wheat and rye DL stabilized A-W interfaces.

Fig. 4 shows that the magnitude of $\left|\mathrm{K}^{*}\right|$ of control rye DL stabilized A-W interfaces $(128 \mathrm{mN} / \mathrm{m})$ was significantly $(\mathrm{P}<0.05)$ higher than that of control wheat DL stabilized A-W interfaces $(26 \mathrm{mN} / \mathrm{m})$. This implies that the film formed at control rye DL stabilized A-W interfaces was effectively more viscoelastic than the A-W interfacial film formed by control wheat DL constituents. While the $\left|\mathrm{K}^{*}\right|$ values of control and enzyme-treated wheat DL stabilized A-W interfaces were similar, $\left|\mathrm{K}^{*}\right|$ of an enzyme-treated rye DL stabilized A-W interface $(46 \mathrm{mN} / \mathrm{m})$ was much lower than that of A-W interfaces stabilized by control rye DL constituents $(128 \mathrm{mN} / \mathrm{m})$. This implies that non-hydrolyzed rye DL AX molecules increase the viscoelasticity and thus the strength of the adsorbed film to a greater extent than their enzymatically released hydrolysis products. 


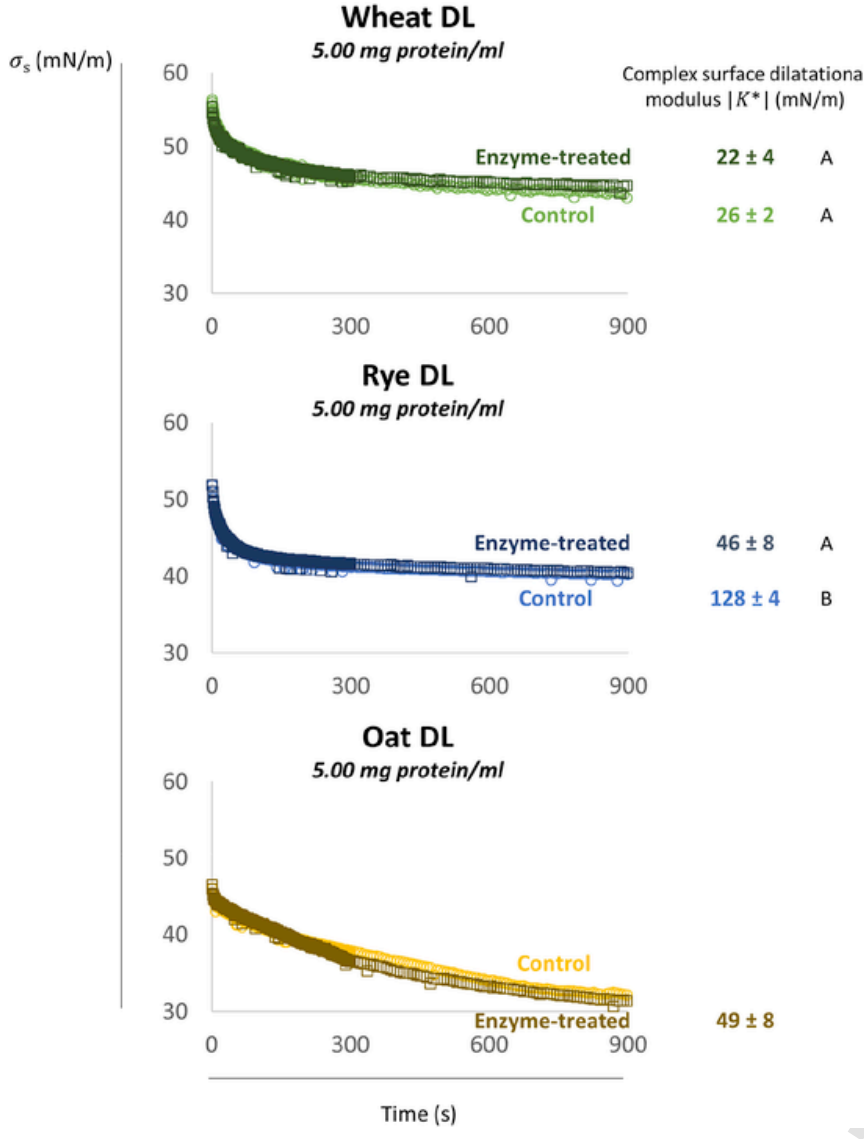

Fig. 4. Evolution of surface tension $\left(\sigma_{s}\right)$ as function of time and the magnitude of the complex surface dilatational modulus $\left(\left|\mathrm{K}^{*}\right|\right)$ of the A-W interface of a pendant drop of control (circles) and enzyme-treated (squares) wheat (green), rye (blue), and oat (yellow) DLs (all at $5.00 \mathrm{mg}$ protein $/ \mathrm{mL}$ ), as measured by drop shape tensiometry. Error values represent the deviation from the mean for duplicate measurements of two separate DL isolation experiments. $\left|\mathrm{K}^{*}\right|$ values with the same capital letter for a given DL are not significantly different $(\alpha=0.05)$. (For interpretation of the references to color in this figure legend, the reader is referred to the Web version of this article.)

We did not report $\left|\mathrm{K}^{*}\right|$ of control oat DL stabilized A-W interfaces because its viscous component $\left(\mathrm{K}^{\prime \prime}\right)$ was negative. This confirms that the Young-Laplace equation used for fitting the shape of the droplet during the subsequent oscillations was not valid. In pendant drop tensiometry measurements the capillary number is assumed to be very low (Jaensson \& Vermant, 2018; Leser, Acquistapace, Cagna, Makievski, \& Miller, 2005). This number expresses the ratio between viscous and $\sigma$ forces and thus increases when the bulk viscosity increases as well. In such cases, the shape of the droplet can be considered to not be in an equilibrium state, which would render the Young-Laplace equation invalid (Jaensson \& Vermant, 2018; Leser et al., 2005). Thus, the negative $\mathrm{K}^{\prime \prime}$ value of control oat DL stabilized A-W interfaces may be associated with the high bulk viscosity of oat DL at $5.00 \mathrm{mg}$ protein/ $\mathrm{mL}$. That positive $\mathrm{K}^{\prime \prime}$ values were obtained when the oat DL bulk viscosity was substantially decreased by enzymatically hydrolyzing its $\beta$-D-glucans supports this hypothesis. The magnitude of $\mathrm{K}^{\prime \prime}$ an enzyme-treated oat DL stabilized A-W interface (Fig. 4) was similar to that of an enzyme-treated rye DL A-W interfacial film and significantly $(\mathrm{P}<0.05)$ higher than that of an enzyme-treated wheat DL stabilized A-W interface. This suggests that enzyme-treated oat and rye DL constituents form more viscoelastic A-W interfacial films than those in enzyme-treated wheat DLs.

\subsubsection{Stress-controlled interfacial shear rheometry}

Interfacial shear rheology measurements are most valuable for studying interactions between constituents adsorbed at A-W interfaces as the interfacial area is constant and shear viscosities are sensitive to lateral interactions between said constituents (Dickinson, 2011; Krägel, Derkatch, \& Miller, 2008). Fig. 5 shows the evolution of $\left|\eta^{*} s\right|, \eta^{\prime \prime}$, and $\eta^{\prime}$ s over time of A-W interfaces stabilized by constituents in control and enzyme-treated wheat and rye DLs (all at $1.50 \mathrm{mg}$ protein $/ \mathrm{mL}$ ).

At $0.50 \mathrm{~Hz}, \mathrm{~A}-\mathrm{W}$ interfaces formed by adsorption of control wheat DL constituents were predominantly viscous $\left(\eta^{\prime} s>\eta_{s}\right.$ s) during the first $30 \mathrm{~min}$ and predominantly elastic $\left(\eta^{\prime \prime}{ }_{s}>\eta^{\prime}{ }_{s}\right)$ thereafter (Fig. 5). This was reflected in the evolution of $\delta_{\mathrm{s}}$ over time, which decreased from 60 to $45^{\circ}$ during the first $30 \mathrm{~min}$ and from 45 to $28^{\circ}$ afterwards (see supplementary information). In contrast, $\mathrm{A}-\mathrm{W}$ interfaces formed by adsorption of the constituents in control rye DLs at $0.50 \mathrm{~Hz}$ were predominantly viscous $\left(\eta_{s}^{\prime}>\eta^{\prime \prime}{ }_{s}\right)$ over the entire measurement time frame (Fig. 5) and characterized by a constant $\delta_{S}\left(66^{\circ}\right.$, see supplementary information). Oscillatory frequency sweeps performed immediately after the time sweep also showed that control wheat and rye DL stabilized A-W interfaces were predominantly elastic $\left(\eta^{\prime \prime} s>\eta_{s}^{\prime}\right)$ and viscous $\left(\eta^{\prime} s>\eta^{\prime \prime}\right.$ s), respectively, between 0.50 and $5.00 \mathrm{~Hz}$ (data not shown). Thus, no shift of the dominant relaxation time was observed in both cases. Finally, no reliable shear moduli were obtained for control and enzyme-treated oat DL stabilized A-W interfaces, because the absolute values were below the detection limit (i.e. about $5.0 \times 10^{-6}$ Pa.m.s) of the DWR geometry used in the present study (Vandebril et al., 2010). This is probably because lipids dominate oat DL stabilized A-W interfaces (Janssen et al. submitted for publication). Indeed, in dilute surfactant solutions the area per molecule at the A-W interface is too high to generate a measurable response when deformed under shear (Zell, Nowbahar, Mansard, Leal, Deshmukh et al., 2014).

In contrast, enzymatic hydrolysis of wheat DL AX resulted in it having a pronouncedly higher $\left|\eta^{*}{ }_{s}\right|$ over the entire measurement time frame. In contrast to what was observed for control wheat DLs, the A-W interfacial film of enzyme-treated wheat DL constituents was predominantly viscous $\left(\eta_{s}^{\prime}>\eta_{s}^{\prime \prime}\right)$ at $0.50 \mathrm{~Hz}$ during the first $8 \mathrm{~min}$ and predominantly elastic $\left(\eta^{\prime \prime}{ }_{s}>\eta^{\prime}\right.$ s) between 8 and $126 \mathrm{~min}$. It thus seems that wheat DL surface-active constituents - in the presence of non-hydrolyzed AX - need more time to develop a predominantly elastic A-W interfacial film. Furthermore, A-W interfaces stabilized by enzyme-treated wheat DL had higher $\eta^{\prime \prime}{ }_{s}$ and $\eta_{s}^{\prime}$ values $\left(7.73 \times 10^{-4}\right.$ Pa s.m and $4.41 \times 10^{-4}$ Pa s.m, respectively) after $126 \mathrm{~min}$ than the corresponding ones from control wheat DL (4.25 $\times 10^{-4}$ Pa s.m and $2.25 \times 10^{-4}$ Pa s.m, respectively). Moreover, that the films from enzyme-treated wheat DL were characterized by slightly lower $\delta_{\mathrm{s}}$ values (a decrease from 50 to $23^{\circ}$ was observed over $126 \mathrm{~min}$ ) than those from control DL (a decrease from 60 to $28^{\circ}$ was observed over $126 \mathrm{~min}$ ) implies that the hydrolysis of AX led to a relatively greater increase of $\eta^{\prime \prime}{ }_{s}$ than of $\eta^{\prime}$. Assuming that non-hydrolyzed wheat DL AX molecules did not adsorb at the A-W interface and did not change the surface activity of the other DL constituents (section 3.4.1, Fig. 4), it seems reasonable to suggest that they altered the microstructure of the A-W interfacial film by interacting with proteins already adsorbed at it. Since AX carries no charge (Courtin \& Delcour, 2002), these interactions are likely mostly hydrogen bonds (Rodríguez Patino \& Pilosof, 2011). However, that enzymatic hydrolysis of AX led to an increase of the magnitude of $\left|\eta^{*}\right|$ implies that non-hydrolyzed AX impairs mutual protein-protein interactions at wheat DL stabilized A-W interfaces to a larger extent than hydrolyzed AX. We speculate that non-hydrolyzed $\mathrm{AX}$ molecules make adsorbed proteins less available for interaction, presumably by occupying hydrogen bonding sites and/or by exerting steric hindrance. However, it must be noted that the enzymatically re- 


\section{Rye DL \\ $1.50 \mathrm{mg}$ protein $/ \mathrm{ml}$}

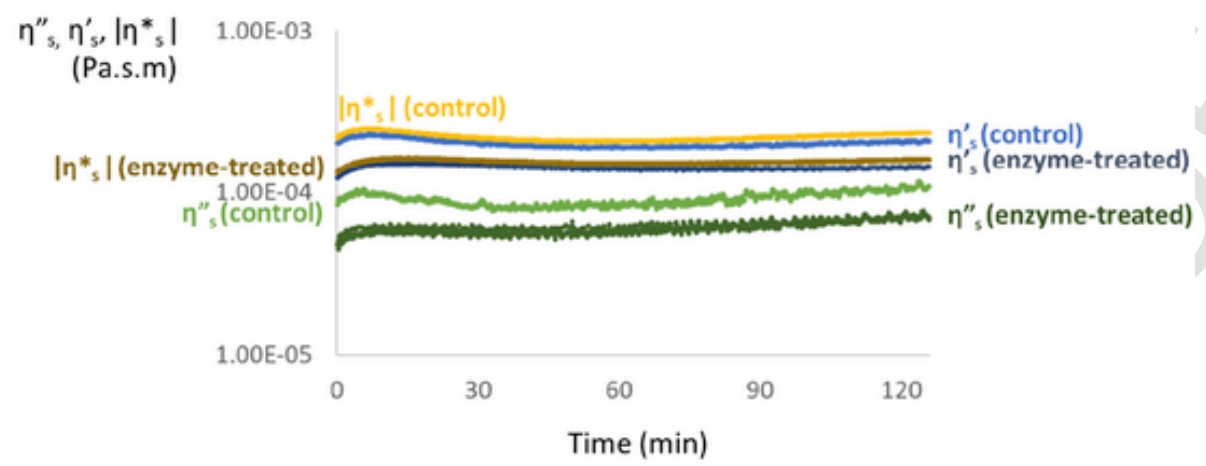

\section{Wheat DL $1.50 \mathrm{mg}$ protein $/ \mathrm{ml}$}

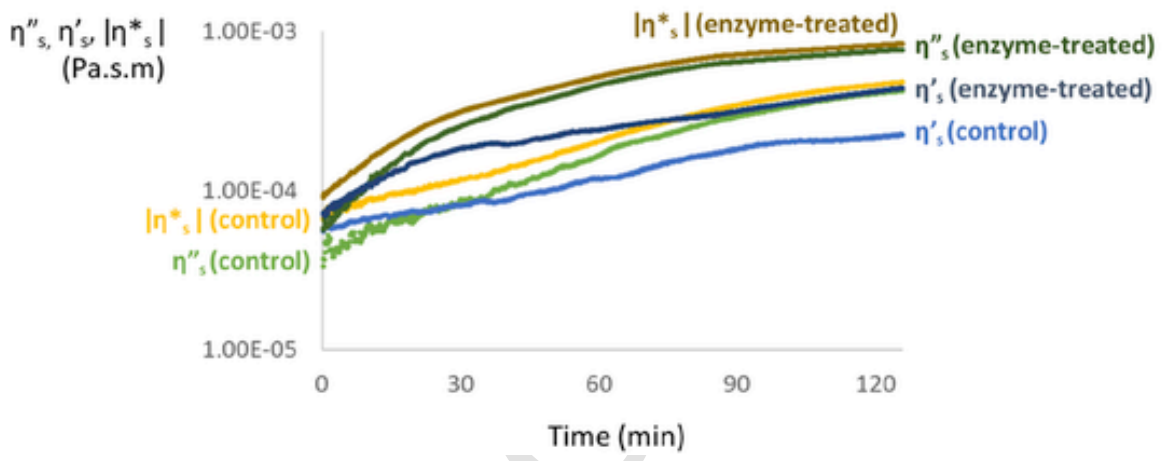

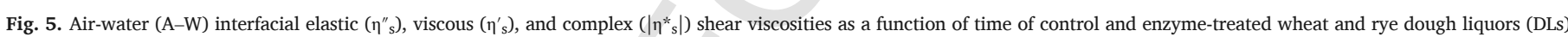

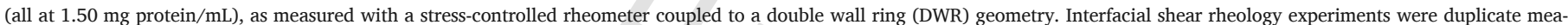
surements on DLs from each of two separate isolations.

leased wheat DL AX hydrolysis products may still contribute to the $\left|\eta{ }_{s}\right|$ of the enzyme-treated A-W interfacial film, although most likely to a lesser extent than prior to hydrolysis. Sarker et al. (1998) speculated that the population of (non-hydrolyzed) AX in wheat flour may improve the stability of A-W interfaces in fermenting wheat dough by interacting with adsorbed proteins. However, under the conditions used here, our findings seem to disprove this hypothesis.

In contrast to what was observed for wheat DL, enzymatic hydrolysis of rye DL AX resulted in a small decrease of $\left|\eta^{*}\right|$. Similar to control rye DL stabilized A-W interfacial films, enzyme-treated rye DL stabilized films were predominantly viscous $\left(\eta^{\prime}{ }_{s}>\eta^{\prime \prime}{ }_{s}\right)$ at $0.50 \mathrm{~Hz}$ during $126 \mathrm{~min}$. However, control rye DL stabilized films had higher $\eta^{\prime \prime}{ }_{s}$ and $\eta^{\prime} s$ values $\left(1.08 \times 10^{-4}\right.$ and $2.09 \times 10^{-4} \mathrm{~Pa} \mathrm{s.m}$, respectively, after $\left.126 \mathrm{~min}\right)$ than the enzyme-treated films $\left(\eta^{\prime \prime}{ }_{s}\right.$ and $\eta_{s}^{\prime}$ values of $6.81 \times 10^{-5}$ and $1.43 \times 10^{-4}$, respectively, after $126 \mathrm{~min}$ ). That the enzymatic treatment did not affect the evolution of $\delta_{\mathrm{s}}$ over time at $0.50 \mathrm{~Hz}$ (see supplementary information) shows that the relative decreases of $\eta^{\prime \prime}$ s and $\eta^{\prime}$ s as a result of AX hydrolysis were similar. In section 3.4.1, it was reasoned that non-hydrolyzed rye DL AX themselves do not directly adsorb at the A-W interface. The lower $\left|\eta^{*}{ }^{*}\right|$ of A-W interfaces stabilized by enzyme-treated rye DL constituents than that of the respective control DLs thus indicates a more pronounced strengthening by non-hydrolyzed than by hydrolyzed AX of the A-W interfacial film of rye DL constituents. Non-hydrolyzed AX molecules likely form a secondary layer at the A-W interface by interaction with the primarily adsorbed protein layer. As noted above, the interactions between non- hydrolyzed AX and adsorbed proteins are probably hydrogen bonds. However, the enzymatically released rye DL AX hydrolysis products may still have an impact on the magnitude of $\left|\eta^{*}{ }_{s}\right|$ of A-W interfaces stabilized by enzyme-treated rye DL constituents, although most likely to a less pronounced extent than was the case prior to hydrolysis.

Even though proteins and lipids co-exist at interfaces stabilized by both wheat and rye DLs (Janssen et al. submitted for publication), the impact of non-hydrolyzed AX was different in both cases. Indeed, while non-hydrolyzed rye DL AX strengthened the A-W interfacial film, non-hydrolyzed wheat DL AX seemed to weaken it. One possible explanation for this is that lipids at the wheat DL stabilized A-W interface interfere with the formation of a coherent protein film at such A-W interfaces (Janssen et al. submitted for publication). In this view, interactions between adsorbed protein and non-hydrolyzed AX molecules would not further strengthen the A-W interfacial film. Alternatively, the ability of AX molecules to interact with the film at wheat and rye DL stabilized A-W interfaces may also be associated with the inherent rheological properties of said film. A-W interface shear rheological measurements showed that rye DL stabilized A-W interfaces were predominantly viscous, whereas wheat DL stabilized A-W interfaces were predominantly elastic (Fig. 5). This evidently indicates that the microstructure of and thus the interactions between adsorbed constituents in both films are different. This is most likely related to structural and compositional differences between wheat and rye DL proteins. Indeed, predominantly elastic A-W interfacial films (e.g. $\beta$-lactoglobulin films) behave like a solid and are in a 'physically fixed state' (Cicuta, 2007; 
Krägel et al., 2008). In contrast, predominantly viscous A-W interfacial protein films (e.g. $\beta$-casein films) are fluid-like and are in a "physically mobile state' (Bantchev \& Schwartz, 2003; Cicuta, 2007; Krägel et al., 2008). We speculate that A-W interfacial films with a predominantly viscous shear response (rye DL stabilized A-W interfaces) are more susceptible to strengthening by non-hydrolyzed AX present in the bulk phase than A-W interfacial films characterized by an elastic dominant shear response (wheat DL stabilized A-W interfaces). In addition, the concentration and structure (molecular weight, degree of substitution, and substitution pattern) of AX may play a role in determining its interaction with adsorbed molecules. It is therefore important to mention that the concentration of non-hydrolyzed AX in control wheat DL at $1.50 \mathrm{mg}$ protein $/ \mathrm{mL}(0.8 \mathrm{mg} / \mathrm{mL})$ was much lower than that in control rye DL at $1.50 \mathrm{mg}$ protein $/ \mathrm{mL}(1.6 \mathrm{mg} / \mathrm{mL})$. Additionally, the WE-AX in wheat flour generally has a much higher level of unsubstituted xyloses (50-80\%) (Cleemput et al., 1995) than that in rye flour (22-54\%) (Vinkx, Delcour, Verbruggen, \& Gruppen, 1995). To what extent the structural features of non-hydrolyzed AX have an impact on its potential to interact with adsorbed surface-active constituents has, far as we are aware, not yet been studied.

In conclusion, NSPs had no impact on the rate or extent at which $\sigma_{s}$ of A-W interfaces stabilized by wheat, rye, or oat DL decreased over time.

Enzyme-treated wheat DL constituents resulted in significantly ( $\mathrm{P}<0.05)$ lower foaming capacities than was the case for control wheat DLs (Fig. 2). Despite this, non-hydrolyzed wheat DL AX seem to impair the degree to which protein-protein interactions occur at the A-W interface. This seems to suggest that the lower foaming capacity of enzyme-treated wheat DL constituents may at least to an extent be related to the lower $\eta_{\text {bulk }}$ of enzyme-treated wheat DLs. However, the foaming properties of control wheat DLs were still inferior over those of control rye DLs. The poor foaming properties of wheat DL may be ascribed to a combined effect of (i) low $\eta_{\text {bulk, }}$, (ii) co-occurrence of proteins and lipids at the A-W interface, and (iii) unfavorable interactions between non-hydrolyzed $\mathrm{AX}$ and adsorbed protein molecules at the $\mathrm{A}-\mathrm{W}$ interface.

In contrast to what occurred for wheat DL, a cooperative effect involving a multilayer structure comprised of proteins as primary layer and non-hydrolyzed AX as secondary layer may explain the high $\left|\eta^{*}\right|$ of rye DL stabilized A-W interfacial films. Hence, the excellent foaming properties of rye DL constituents are most likely associated with (i) the high $\eta_{\text {bulk }}$ and (ii) the formation of a multilayer structure between proteins and non-hydrolyzed $\mathrm{AX}$ at the $\mathrm{A}-\mathrm{W}$ interface.

Finally, the shear moduli of oat DL stabilized A-W interfaces - irrespective of whether $\beta$-D-glucans were present or not - were below the detection limit of the DWR geometry. It thus seems that oat DL $\beta$-D-glucans only contribute to the stability of oat DL foams by increasing $\eta_{\text {bulk. }}$.

The ability of non-hydrolyzed NSPs to strengthen the adsorbed A-W interfacial film seems to be related to the composition and microstructure of the interface. In earlier work, a defatting procedure was used to investigate the interplay between lipids and proteins (but not of NSPs) at wheat, rye and oat DL constituent stabilized interfaces (Janssen et al. submitted for publication). In the absence of lipids, proteins and NSPs evidently determine the A-W interfacial properties of DL. In what follows, the air-water interfacial properties of defatted and defatted + enzyme-treated wheat, rye, and oat DLs are compared.

\subsection{Impact of enzymatic hydrolysis of non-starch polysaccharides on the interfacial shear rheometry of defatted dough liquor constituents}

Fig. 6 shows the evolution of $\left|\eta^{*}{ }_{s}\right|, \eta^{\prime \prime}$ s, and $\eta^{\prime}{ }_{s}$ over time of A-W interfaces stabilized by defatted and defatted + enzyme-treated wheat and rye DLs (all at $1.50 \mathrm{mg}$ protein $/ \mathrm{mL}$ ). Also in the absence of lipids did enzymatic hydrolysis of wheat DL AX result in a pronounced in- crease of $\eta^{*}$ s over the entire measurement time frame. Furthermore, defatted wheat DL constituents in the presence of non-hydrolyzed AX formed A-W interfacial films with lower $\eta^{\prime \prime}{ }_{s}$ and $\eta^{\prime}$ s values $\left(5.52 \times 10^{-4}\right.$ and $3.26 \times 10^{-4} \mathrm{~Pa}$ s.m, respectively, after $126 \mathrm{~min}$ ) than was the case when AX had been hydrolyzed $\left(1.12 \times 10^{-3}\right.$ and $5.71 \times 10^{-4}$ Pa s.m, respectively, after $126 \mathrm{~min}$ ). It thus seems that non-hydrolyzed wheat DL AX weakens the adsorbed protein film. This effect was also observed when lipids were still present in wheat DL (see section 3.4.2). That this effect takes place irrespective of the absence or presence of lipids at the A-W interface is not in line with the hypothesis that the mixed protein-lipid film at control wheat DL stabilized A-W interfaces is not sufficiently coherent for non-hydrolyzed AX to strengthen it. In the case of defatted rye DL, the impact of non-hydrolyzed AX on $\left|\eta^{*} s\right|$ of the adsorbed protein film was even more pronounced than was the case for control rye DL stabilized films. Indeed, in the absence of lipids, rye DL non-hydrolyzed AX further increased the $\left|\eta^{*}{ }_{s}\right|, \eta^{\prime \prime}$ s, and $\eta^{\prime}$ s values of the A-W interfacial film (Fig. 6). Additionally, the evolution of $\delta_{s}$ over time showed that non-hydrolyzed AX led to a more pronounced increase of $\eta^{\prime \prime}{ }_{s}$ than of $\eta^{\prime}$ s (a further decrease in $\delta_{s}$ of $11^{\circ}$ was observed during the first $83 \mathrm{~min}$, see supplementary information). That the film strengthening by non-hydrolyzed rye DL AX was more pronounced when lipids had been removed by defatting implies that rye DL lipids restrict the potential of non-hydrolyzed $\mathrm{AX}$ to act as a secondary stabilizing layer. More research is needed to clarify whether the difference between wheat and rye DL stabilized films is related to differences in the structures of non-hydrolyzed wheat and rye DL AX, in the microstructure of the adsorbed protein layer, or in both. Finally, the shear moduli of A-W interfaces formed by the constituents in defatted + enzyme-treated oat DL were again below the detection limit of the DWR geometry.

An important side-note is that the evolutions of $\left|\eta^{*} s\right|, \eta^{\prime \prime}$, and $\eta^{\prime}$ s over time of A-W interfaces stabilized by the constituents in defatted + enzyme-treated wheat and rye DLs are a measure for the inherent ability of the proteins present in the DLs to provide stability to the A-W interface (Fig. 7). These data demonstrate that rye DL proteins (i) have higher surface activity than wheat DL proteins and (ii) form A-W interfacial films with a higher magnitude of $\left|\eta^{*}{ }_{s}\right|$ than do wheat DL proteins. The shear rheology of oat DL proteins at A-W interfaces could not be assessed because we were not able to remove all oat DL lipids without affecting the solubility of the other oat DL constituents (Janssen et al. submitted for publication).

\section{Conclusions}

We identified the role of NSPs and their mutual interplay with proteins and lipids in determining the stability of A-W interfaces formed by adsorption of wheat, rye, and oat DL constituents. Fig. 8 provides a graphical overview of the A-W interfacial composition and mutual interactions thereat of control and enzyme-treated wheat, rye, and oat DL stabilized A-W interfaces. These insights were obtained by evaluating the foaming properties, bulk shear rheology, and A-W interfacial properties of wheat and rye DLs - treated with and without xylanase - and oat DL - treated with and without lichenase and $\beta$-D-glucosidase. Non-hydrolyzed NSPs had a positive impact on the foaming capacity of wheat, rye, and oat DLs. Enzymatic hydrolysis of the NSPs drastically reduced $\eta_{\text {bulk }}$ of rye, oat, and wheat DLs. In the case of wheat DL, non-hydrolyzed AX resulted in a pronounced decrease of the magnitude of $\left|\eta^{*}{ }_{s}\right|$. This implies that non-hydrolyzed wheat DL AX interferes with the interactions between adsorbed proteins. In contrast, non-hydrolyzed rye DL AX led to an increase of both $\left|\mathrm{K}^{*}\right|$ and $\left|\eta^{*}{ }_{s}\right|$ of the A-W interfacial film presumably because they form a multilayer below it by means of interactions with adsorbed proteins. Finally, the role of non-hydrolyzed oat DL $\beta$-D-glucans seems to be restricted to their viscosifying properties. Altogether, we identified the role of wheat, rye, and oat DL NSPs in determining the $\eta_{\text {bulk }}$ and their mutual interactions with pro- 


\section{Wheat DL}

$1.50 \mathrm{mg}$ protein $/ \mathrm{ml}$

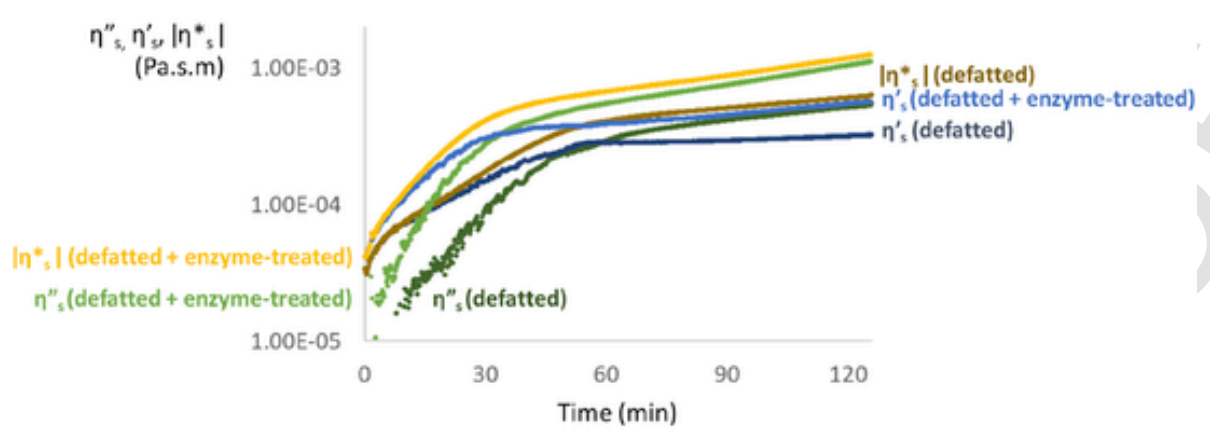

Rye DL

$1.50 \mathrm{mg}$ protein/ml

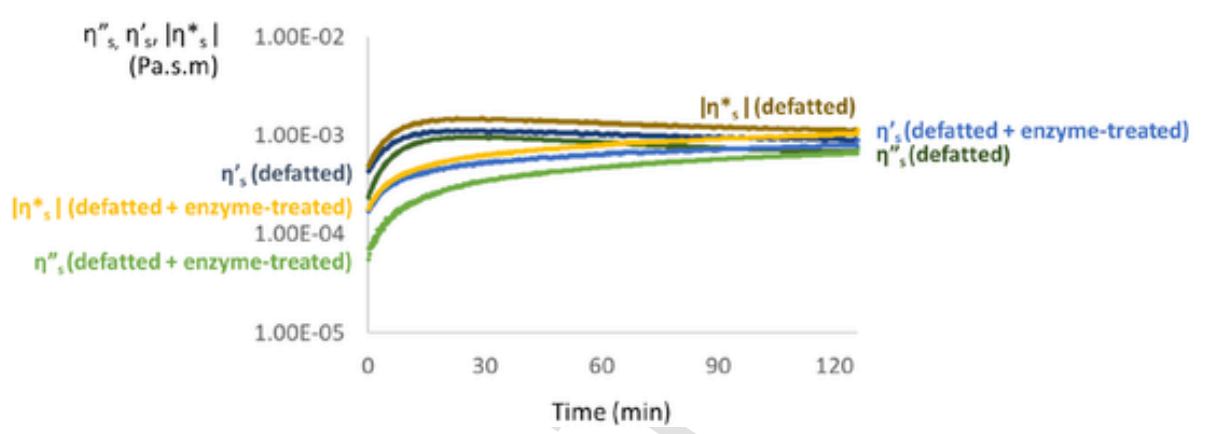

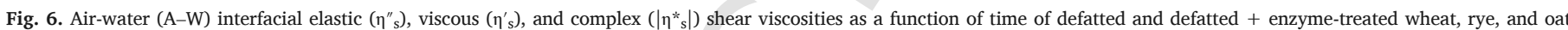

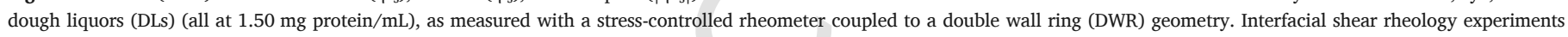
were single measurements on DLs from each of two separate isolations.

\section{Defatted + enzyme-treated DL $1.50 \mathrm{mg}$ protein/ml}

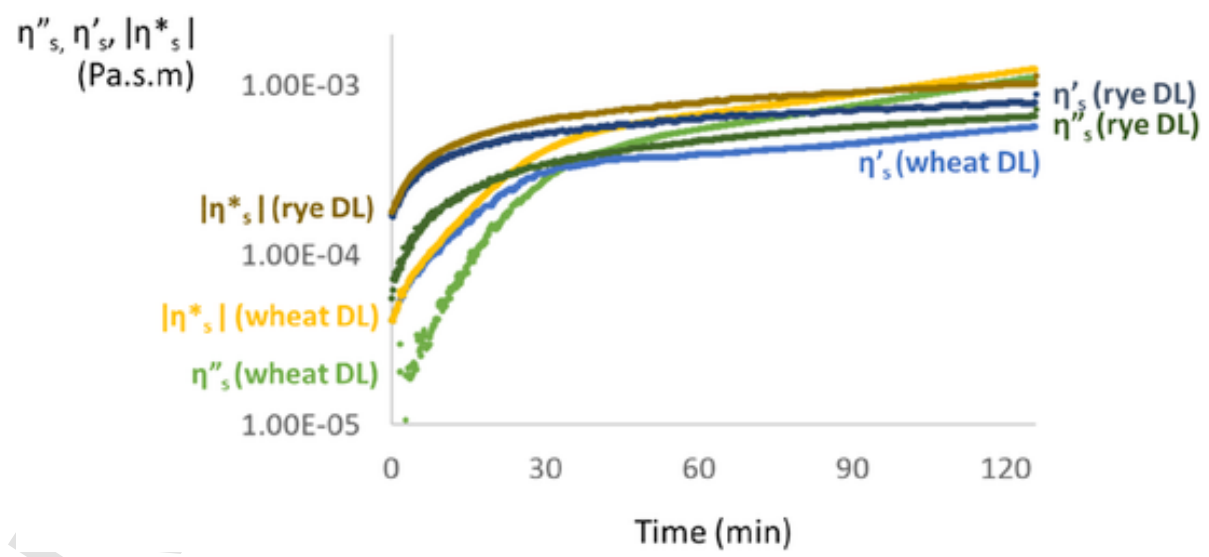

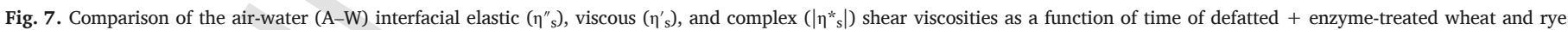

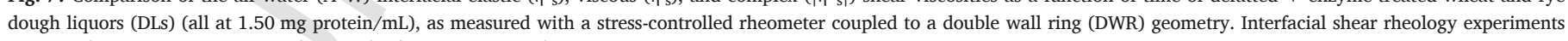
were single measurements on DLs from each of two separate isolations.

teins and lipids at A-W interfaces. Such relationships are of essence for tailoring the aqueous phase composition in wheat, rye, and oat doughs - for example by grain breeding (Gebruers, Dornez, Boros, Fraś, Dynkowska et al., 2008) or enzymatic strategies - to improve the dough gas cell stability and, hence, bread quality.

\section{CRediT authorship contribution statement}

Frederik Janssen: Conceptualization, Methodology, Investigation, Writing - original draft. Arno G.B. Wouters: Conceptualization, Writing - review \& editing. Yannick Meeus: Investigation, Writing - review \& editing. Paula Moldenaers: Writing - review \& editing. Jan Ver- 

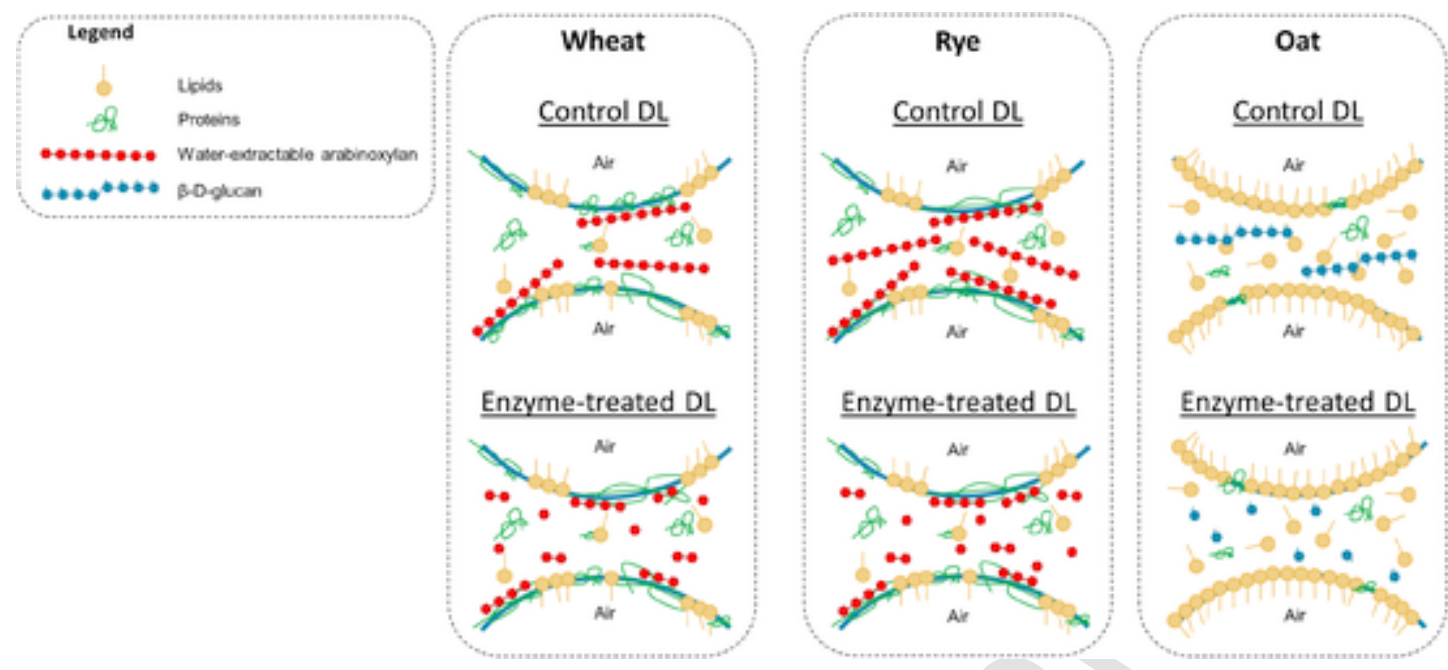

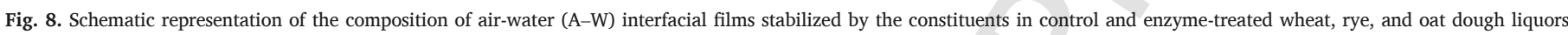

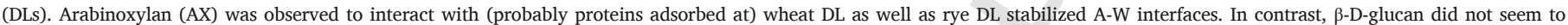
interact with the lipids adsorbed at oat DL stabilized A-W interfaces.

mant: Writing - review \& editing. Jan A. Delcour: Conceptualization, Writing - review \& editing.

\section{Acknowledgements}

Frederik Janssen would like to thank Sarah Pycarelle and Sara Melis for fruitful discussions. Frederik Janssen and Arno Wouters gratefully acknowledge the Research Foundation - Flanders (FWO -Vlaanderen, Brussels, Belgium) for positions as doctoral and postdoctoral researchers, respectively. Jan A. Delcour is W.K. Kellogg Chair in Cereal Science and Nutrition at KU Leuven. This work is part of the Methusalem program "Food for the Future".

\section{Appendix A. Supplementary data}

Supplementary data to this article can be found online at https://doi. org/10.1016/j.foodhyd.2020.105771.

\section{References}

Baker, J., Parker, H., \& Mize, M. (1946). Supercentrifugates from dough. Cereal Chemistry, 23, 16-30.

Bantchev, G. B., \& Schwartz, D. K. (2003). Surface shear rheology of $\beta$-casein layers at the air/solution interface: Formation of a two-dimensional physical gel. Langmuir, 19(7), 2673-2682.

Bengtsson, S., Åman, P., \& Andersson, R. E. (1992). Structural studies on water-soluble arabinoxylans in rye grain using enzymatic hydrolysis. Carbohydrate Polymers, 17(4), $277-284$

Bligh, E. G., \& Dyer, W. J. (1959). A rapid method of total lipid extraction and purification. Canadian Journal of Biochemistry and Physiology, 37, 911-917.

Cicuta, P. (2007). Compression and shear surface rheology in spread layers of $\beta$-casein and $\beta$-lactoglobulin. Journal of Colloid and Interface Science, 308(1), 93-99.

Cleemput, G., Roels, S. P., van Oort, M., Grobet, P. J., \& Delcour, J. A. (1993). Heterogeneity in the structure of water-soluble arabinoxylans in european wheat flours of variable bread-making quality. Cereal Chemistry, 70, 324-329.

Cleemput, G., van Oort, M., Hessing, M., Bergmans, M. E. F., Gruppen, H., \& Grobe, P. J., et al. (1995). Variation in the degree of d-xylose substitution in arabinoxylans extracted from a european wheat flour. Journal of Cereal Science, 22(1), 73-84.

Courtin, C. M., \& Delcour, J. A. (2001). Relative activity of endoxylanases towards water-extractable and water-unextractable arabinoxylan. Journal of Cereal Science, 33(3), 301-312.

Courtin, C. M., \& Delcour, J. A. (2002). Arabinoxylans and endoxylanases in wheat flour bread-making. Journal of Cereal Science, 35(3), 225-243.

Courtin, C., Gelders, G., \& Delcour, J. (2001). Use of two endoxylanases with different substrate selectivity for understanding arabinoxylan functionality in wheat flour breadmaking. Cereal Chemistry, 78(5), 564-571.

Delcour, J. A., Vanhamel, S., \& De Geest, C. (1989). Physico-chemical and functional properties of rye nonstarch polysaccharides. I. Colorimetric analysis of pentosans and their relative monosaccharide compositions in fractionated (milled) rye products. Cereal Chemistry, 66, 107-111.

Dickinson, E. (2011). Mixed biopolymers at interfaces: Competitive adsorption and multilayer structures. Food Hydrocolloids, 25(8), 1966-1983.
Englyst, H. N., \& Cummings, J. H. (1984). Simplified method for the measurement of total non-starch polysaccharides by gas-liquid chromatography of constituent sugars as alditol acetates. Analyst, 109(7), 937-942.

Gan, Z., Angold, R., Williams, M., Ellis, P., Vaughan, J., \& Galliard, T. (1990). The microstructure and gas retention of bread dough. Journal of Cereal Science, 12(1), 15-24.

Gan, Z., Ellis, P., \& Schofield, J. (1995). Gas cell stabilisation and gas retention in wheat bread dough. Journal of Cereal Science, 21(3), 215-230.

Gebruers, K., Dornez, E., Boros, D., Fraś, A., Dynkowska, W., \& Bedő, Z., et al. (2008). Variation in the content of dietary fiber and components thereof in wheats in the healthgrain diversity screen. Journal of Agricultural and Food Chemistry, 56(21), 9740-9749.

Gerits, L. R., Pareyt, B., Masure, H. G., \& Delcour, J. A. (2015). Native and enzymatically modified wheat (triticum aestivum L.) endogenous lipids in bread making: A focus on gas cell stabilization mechanisms. Food Chemistry, 172, 613-621.

Jaensson, N., \& Vermant, J. (2018). Tensiometry and rheology of complex interfaces. Current Opinion in Colloid \& Interface Science, 37, 136-150.

Janssen, F., Wouters, A. G. B., Pauly, A., \& Delcour, J. A. (2018). Relating the composition and air/water interfacial properties of wheat, rye, barley, and oat dough liquor. Food Chemistry, 264, 126-134.

Knoche, S., Vella, D., Aumaitre, E., Degen, P., Rehage, H., \& Cicuta, P., et al. (2013). Elastometry of deflated capsules: Elastic moduli from shape and wrinkle analysis. Langmuir, 29(40), 12463-12471.

Krägel, J., Derkatch, S. R., \& Miller, R. (2008). Interfacial shear rheology of protein-surfactant layers. Advances in Colloid and Interface Science, 144(1), 38-53.

Leser, M. E., Acquistapace, S., Cagna, A., Makievski, A. V., \& Miller, R. (2005). Limits of oscillation frequencies in drop and bubble shape tensiometry. Colloids and Surfaces A: Physicochemical and Engineering Aspects, 261(1), 25-28.

Loosveld, A.-M. A., Grobet, P. J., \& Delcour, J. A. (1997). Contents and structural features of water-extractable arabinogalactan in wheat flour fractions. Journal of Agricultural and Food Chemistry, 45(6), 1998-2002.

MacRitchie, F. (1976). Liquid phase of dough and its role in baking. Cereal Chemistry, 53(3), 318-326.

MacRitchie, F., \& Gras, P. (1973). The role of flour lipids in baking. Cereal Chemistry, 50, 292-302.

McCleary, B. V., \& Nurthen, E. (1986). Measurement of (1-3)(1-4)- $\beta$-d-glucan in malt, wort and beer. Journal of the Institute of Brewing, 92(2), 168-173.

Melis, S., Pauly, A., Gerits, L. R., Pareyt, B., \& Delcour, J. A. (2017). Lipases as processing aids in the separation of wheat flour into gluten and starch: Impact on the lipid population, gluten agglomeration, and yield. Journal of Agricultural and Food Chemistry, 65(9), 1932-1940.

Mills, E., Wilde, P., Salt, L., \& Skeggs, P. (2003). Bubble formation and stabilization in bread dough. Food and Bioproducts Processing, 81(3), 189-193.

Murray, B. S. (2007). Stabilization of bubbles and foams. Current Opinion in Colloid \& Interface Science, 12(4), 232-241.

Nagel, M., Tervoort, T. A., \& Vermant, J. (2017). From drop-shape analysis to stress-fitting elastometry. Advances in Colloid and Interface Science, 247, 33-51.

Pauly, A., \& Delcour, J. A. (2018). Impact of cereal water-extractable components on oat bread quality. Journal of Cereal Science, 79, 134-140.

Pauly, A., Pareyt, B., Fierens, E., \& Delcour, J. A. (2014). Fermentation affects the composition and foaming properties of the aqueous phase of dough from soft wheat flour. Food Hydrocolloids, 37, 221-228.

Primo-Martín, C., Hamer, R. J., \& de Jongh, H. H. (2006). Surface layer properties of dough liquor components: Are they key parameters in gas retention in bread dough? Food Biophysics, 1(2), 83-93.

Renggli, D., Alicke, A., Ewoldt, R., \& Vermant, J. (2020). Operating windows for oscillatory interfacial shear rheology. Journal of Rheology, 64(1), 141-160.

Rodríguez Patino, J. M., \& Pilosof, A. M. R. (2011). Protein-polysaccharide interactions at fluid interfaces. Food Hydrocolloids, 25(8), 1925-1937. 
Sahi, S. S. (2003). The interfacial properties of the aqueous phases of full recipe bread doughs. Journal of Cereal Science, 37(2), 205-214.

Salt, L. J., González-Thuillier, I., Chope, G., Penson, S., Tosi, P., \& Haslam, R. P., et al. (2018). Intrinsic wheat lipid composition effects the interfacial and foaming properties of dough liquor. Food Hydrocolloids, 75, 211-222.

Salt, L. J., Robertson, J. A., Jenkins, J. A., Mulholland, F., \& Mills, E. (2005). The identification of foam-forming soluble proteins from wheat (triticum aestivum) dough. Proteomics, 5(6), 1612-1623.

Salt, L. J., Wilde, P., Georget, D., Wellner, N., Skeggs, P., \& Mills, E. (2006). Composition and surface properties of dough liquor. Journal of Cereal Science, 43(3), 284-292.

Sarker, D., Wilde, P., \& Clark, D. (1998). Enhancement of protein foam stability by formation of wheat arabinoxylan-protein crosslinks. Cereal Chemistry, 75(4), 493-499.

Sroan, B. S., Bean, S. R., \& MacRitchie, F. (2009). Mechanism of gas cell stabilization in bread making. I. The primary gluten-starch matrix. Journal of Cereal Science, 49(1), $32-40$.

Sroan, B. S., \& MacRitchie, F. (2009). Mechanism of gas cell stabilization in breadmaking. II. The secondary liquid lamellae. Journal of Cereal Science, 49(1), 41-46.

Turbin-Orger, A., Della Valle, G., Doublier, J., Fameau, A.-L., Marze, S., \& Saulnier, L. (2015). Foaming and rheological properties of the liquid phase extracted from wheat flour dough. Food Hydrocolloids, 43, 114-124.

Van den Bulck, K., Swennen, K., Loosveld, A.-M. A., Courtin, C. M., Brijs, K., \& Proost, P., et al. (2005). Isolation of cereal arabinogalactan-peptides and structural comparison of their carbohydrate and peptide moieties. Journal of Cereal Science, 41(1), 59-67.
Vandebril, S., Franck, A., Fuller, G. G., Moldenaers, P., \& Vermant, J. (2010). A double wall-ring geometry for interfacial shear rheometry. Rheologica Acta, 49(2), 131-144.

Vinkx, C. J. A., \& Delcour, J. A. (1996). Rye (secale cereale L.) arabinoxylans: A critical review. Journal of Cereal Science, 24(1), 1-14.

Vinkx, C. J. A., Delcour, J. A., Verbruggen, M. A., \& Gruppen, H. (1995). Rye water-soluble arabinoxylans also vary in their contents of 2-monosubstituted xylose. Cereal Chemistry, 72, 227-228.

Wood, P. J., Weisz, J., \& Blackwell, B. A. (1991). Molecular characterization of cereal beta-d-glucans. Structural analysis of oat beta-d-glucan and rapid structural evaluation of beta-d-glucans from different sources by high-performance liquid chromatography of oligosaccharides released by lichenase. Cereal Chemistry, 68. 31-39.

Wood, P. J., Weisz, J., \& Blackwell, B. A. (1994). Structural studies of (1-3),(1-4)-beta-d-glucans by 13c-nuclear magnetic resonance spectroscopy and by rapid analysis of cellulose-like regions using high-performance anion-exchange chromatography of oligosaccharides released by lichenase. Cereal Chemistry, 71(3), 301-307.

Zell, Z. A., Nowbahar, A., Mansard, V., Leal, L. G., Deshmukh, S. S., \& Mecca, J. M., et al. (2014). Surface shear inviscidity of soluble surfactants. Proceedings of the National Academy of Sciences, 111(10), 3677.

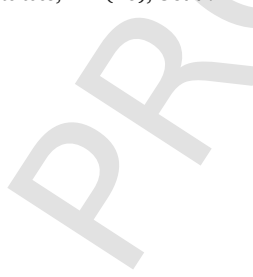

